\title{
Eighty years of macromolecular science: from birth to nano-, bio- and self-assembling polymers - with slight emphasis on European contributions
}

\author{
Hans-Henning Kausch-Blecken von Schmeling
}

Received: 19 May 2011 /Accepted: 1 June 2011 / Published online: 18 June 2011

(C) Springer-Verlag 2011

\begin{abstract}
A definition of macromolecular science (as opposed to polymer science and engineering) is given, from which the year 1930 is derived as the year of its birth. The scope of treatment of this paper will be limited to solid technical polymers. Some important discoveries of polymer technology in the nineteenth century are reviewed together with the reason why the concept of macromolecules and the theory of rubber elasticity did not emerge earlier. The role of chain backbones in structure formation and mechanical loading of technical polymers has been heavily discussed ever since and has attracted this author for most of his scientific work. He offers a personal perspective of the most important achievements in three domains of macromolecular science: the synthesis of well-designed chain molecules, structural characterization and the understanding of the micro-mechanics of (nano-structured) polymer materials. Progress is generally documented by citing individual references from the discussed periods-well knowing that the development of science is due to the contributions of many more people. In conclusion, a critical outlook will be attempted on future trends in the design and application of well-adapted - and frequently complex - polymer systems towards growing human needs.
\end{abstract}

Keywords Early polymer technology. Definition and foundations of macromolecular science - Micro-mechanics . Polymer systems for human needs

H.-H. Kausch-Blecken von Schmeling $(\bowtie)$

Swiss Federal Institute of Technology Lausanne (EPFL),

Lausanne, Switzerland

e-mail: kausch.cully@bluewin.ch

\section{Introduction}

Practically all organic matter is formed from long-chain molecules, and such matter has been used and treated by mankind from the very beginning of time. Producing cotton fibres as people in India have done for more than 7,000 years certainly is a kind of polymer engineering. As opposed to this, we speak of macromolecular science if the extreme length of the constituting chain molecules is clearly recognized. In addition, macromolecular science has the aim to determine and to control: (1) chain length (including methods of synthesis), (2) the physical and geometrical constitution of single chains (configuration, large segmental anisotropies, architecture, conformation) and (3) the arrangement and interaction of chains in liquid and solid state and transitions between such states (vast field: crystallisation, morphology, thermodynamic behaviour, rubber elasticity, interfaces, diffusion). It is for this reason that the term Macromolecular science can only be applied to investigations, which explicitly recognize the long-chain nature of polymer molecules. Following Morawetz [1], the author considers that the Frankfurter Tagung of the Kolloidgesellschaft in September 1930 brought at least an agreement on the fact that high molecular materials exist and warrant specific methods of analysis of constitution and behaviour. This event may be considered, therefore, as the birth of macromolecular science (today synonymous with polymer science $^{1}$ ). To accept the concept of macromolecules was

\footnotetext{
${ }^{1}$ In fact, today it is somewhat arbitrary to distinguish between macromolecular and polymer science, since the word polymer also refers to an enchainment of elements. As opposed to a macromolecule, a polymer is generally seen as the material (Werkstoff), it encompasses the technological aspects, which are anyhow the driving forces in the field.
} 
apparently such a major intellectual step that it prevented prominent and highly knowledgeable colleagues for almost a century to recognize the enormous length of polymer chains.

\section{Early polymer technology 1833-1920}

In his-you may say eye-witness-report, H. Mark [2] traces the use of polymer materials back to biblical times. The author of this review will only follow developments after Berzelius had coined the word polymeric in 1833. Berzelius was intrigued by Faraday's data on the identical elemental composition of butene- $\mathrm{C}_{4} \mathrm{H}_{8}$ - and olefiant gas (ethylene, $\mathrm{C}_{2} \mathrm{H}_{4}$ ). As Morawetz [1] indicates, Berzelius refers in his discussion to-the ill-defined-oil of wine, which may explain in part why the simple concept of adding more identical $\mathrm{CH}_{2}-$ groups to butene was not extended to really long molecules.

Many people studied the behaviour of such materials and early technologically important discoveries were made. Goodyear empirically discovered the vulcanisation of caoutchouc (1839), Schönbein obtained nitrocellulose in 1845 and the Brothers Hyatt produced celluloid (cellulose dinitrate modified by camphor) as a substitute for ivory (1869).

The heating of a rubber band upon extension, first observed by Gough in 1805, was some 50 years later studied by W. Thomson (Lord Kelvin) and Joule. Although Kelvin himself gave a formulation of the Second Law of Thermodynamics, he wrongly predicted the behaviour of a loaded, extended rubber band. Morawetz [1] discusses the controversial interpretations given at that time to the Gough-Joule effect. With Clausius having defined in 1865 the physical quantity entropy and Boltzmann having related in 1873 the entropy to the probability of a physical state, all the theoretical instruments were available to express the entropic origin of the elasticity of natural rubber. To do so it would only have been necessary to count the number of physical states of an (extended) rubber band - and for that an appropriate model of the rubber material was needed. Even such a model could have been available, since Berthelot (18271907) presents in 1863 the first general discussion on polymerization adopting the term polymer proposed by Berzelius. Berthelot claims "that all compounds able to add hydrogen, chlorine, water, must be able to add molecules identical to themselves" [1]. Prophetic words are more or less forgotten for about 60 years.

At the end of the nineteenth century, a multitude of modified and/or fully synthetic polymers came on the market [3], and it is quite appropriate that Mark [2] considers this period as the beginning of Polymer Science and Technology. Following a number of different efforts, Chardonnet silk was in 1885 the first successful man-made fibre, derived from modified cellulose [1, 2]. The first elastomer (isoprene rubber) was - painfully ${ }^{2}$ - synthesized and the first new plastic, the phenolic resin Bakelite ${ }^{\mathbb{Q}}$, which is celebrating in 2011 its 100th anniversary, began its long-lasting career. In the same year 1911, the journal Kunststoffe appeared, then and now dedicated to the production and use of modified and/or synthetic polymer materials. All this work was accomplished without reference to long molecular chains.

\section{Staudinger's struggle for the notion of macromolecules 1920-1930}

The first mention of high molecular polymerization products formed by several hundred Bausteinen (of isoprene or formaldehyde) was made in 1920 by Staudinger, at that time a member of ETH in Zürich [4]. On the basis of his rheological and X-ray studies, he finally coins 4 years later the term Makromolekül in his famous

6. Mitteilung: über die Konstitution des Kautschuks, Berichte der Deutschen Chem. Gesellschaft 57, 1203

(1924)

In 1926 Staudinger was nominated professor in Freiburg/ Breisgau. He continues his work-but his concept of macromolecules is still heavily opposed by Mark and Meyer (and other German chemists), who explained their X-ray, rheological and (preliminary) mechanical data on the basis of micellar aggregates [4]. It must be concluded that even for experienced chemists dedicated to science, the intellectual step to accept the notion of macromolecules had simply been too large. This is even the more surprising as Mark and Meyer at BASF were engaged in the late twenties in the copolymerisation of styrene and butadiene (BUNA S), so they must have been aware of the role of double bonds in chain growth polymerization. As Mark [2] observes in retrospect, much of the animated discussions between himself, Meyer and Staudinger in the late 1920s turned around details, so that an agreement on the main point, namely that high molecular materials exist and warrant specific methods of analysis of constitution and behaviour, was strongly retarded. For his work leading to the identification of the macromolecular nature of polymers, Staudinger was awarded the Nobel Prize in 1953. With the new understanding, progress in all domains of the now macromolecular science was imminent.

\footnotetext{
${ }^{2}$ Shake for 6 weeks at $60{ }^{\circ} \mathrm{C}$
} 


\section{Macromolecular science in the 1930s and 1940s}

Methods of synthesis and analysis of physical behaviour Röhm ${ }^{3}$, Carothers Flory, Schlack, Castan and others [1-3] had considerably extended the knowledge of the different types of polymerization reactions and products: $\mathrm{PVC},{ }^{4} \mathrm{PS}$, (PMMA), LDPE, IR, PBD (Buna) and SBR were produced by chain growth polymerization; PA 6.6, PA 6 and BPAPC by polycondensation techniques, PU and epoxy resins by polyaddition. Progress was also made in experimental analysis: Starting in 1903, W.W. Coblentz [5] had studied the vibrational infrared (IR) spectra of a hundred organic and inorganic materials; the ultracentrifuge was invented in 1925 by Th. Svedberg, who obtained the Nobel Prize a year later; V. Raman had analysed the inelastic photon scattering, effect, which bears his name and for which he had obtained the Nobel Prize in Physics in 1930; X-ray analysis techniques were improved; in 1933, E. Ruska constructed the first transmission electron microscope; for this invention, he was awarded the Nobel Prize 53 years later - together with Binnig and Rohrer; considerable progress was also made in the understanding of the thermodynamics of macromolecular solutions and transitions. All this is detailed in the excellent book of Morawetz [1] and need not be repeated here.

Thus, within less than 10 years, most of the above specified conditions for a macromolecular approach had been fulfilled - except for the fact that configuration and average mass of the chain molecules could be determined but not controlled: No stereoregular and highly linear polyolefins could as yet be synthesized.

Theory of rubber elasticity The recognition of the longchain nature of polymers had particularly stimulated the understanding of rubber elasticity. K.H. Meyer-together with v. Susich and Valko-had argued that the "retractive forces arise from a tendency to pass to a state of higher entropy rather than a state of lower energy". He also proposed that rotational motions of part of the chain must be involved and that the retractive forces should be proportional to the absolute temperature.

This was confirmed by the calculations of Kuhn in 1934, who used a simple model of an elongated chain composed of freely rotating segments. Performing elegant calculations, he was able to quantify the number $\Omega$ of physical states of his model chains as a function of their end-to-end distance $r$. Despite the ideas communicated by Gough, Joule, Boltzmann, Staudinger and Meyer et al. as outlined

\footnotetext{
${ }^{3}$ Well-known names from the polymer community are not referenced individually. In any event, names and references until about 1960 can be found in the book of Morawetz [1].

${ }^{4}$ Standard acronyms are used for polymer names and methods of characterization.
}

above, Kuhn's accomplishment remains absolutely remarkable. Thus, he could relate the Boltzmann equation $S=k$ $\ln \Omega$ to the physical quantities of his model chain:

$S=\mathrm{k} \ln \Omega=3 \mathrm{kr}^{2} / 2 n \mathrm{a}^{2}$

where $k$ is the Boltzmann constant, $r$ the chain end-to-end distance and $n$ the number of freely rotating chain segments of length $a$.

Independently, Guth and Mark obtained in the same year an equivalent result considering valence bond angles. Thus, 14 years after Staudinger's first statement on the length of chain molecules, it was finally agreed that macromolecules are neither long stiff sticks - as originally defended by Staudinger - nor the short, bendable sticky segments as postulated by the micelle model. Again, in retrospective it is easy to be puzzled by both of these highly unsuitable attempts, namely to explain the important flexibility of elastomers by either stiff, unflexible or sticky components. These first models of rubber elasticity were subsequently improved and extended to real rubber networks by a large number of scientists such as, e.g. Mooney, Rivlin, Tobolsky, Mullins, Treloar or Gent [1-3, 6].

The linear dependence of the retractive forces $f$ on temperature $T$ qualitatively predicted by Meyer et al. and derived from the above equation was shortly afterwards corroborated by a convincing experiment as shown in Fig. 1. The above figure beautifully shows a dramatic change of behaviour from energy elastic to entropy elastic at a point designated as glass transition temperature $T_{\mathrm{g}}$. It also confirms the predicted linear dependence of stress on absolute temperature for $T>T_{\mathrm{g}}$.

The arrangement and interaction of chains in solid polymers, polymer solutions and proteins were intensively studied in the following years and led to major advances in the understanding of their behaviour (see [1], part 2). No general attention was paid, however, to the observation of Storks [1, 8] —already made in 1938 - that chain molecules in crystals are folded. Morawetz in his book [1] and

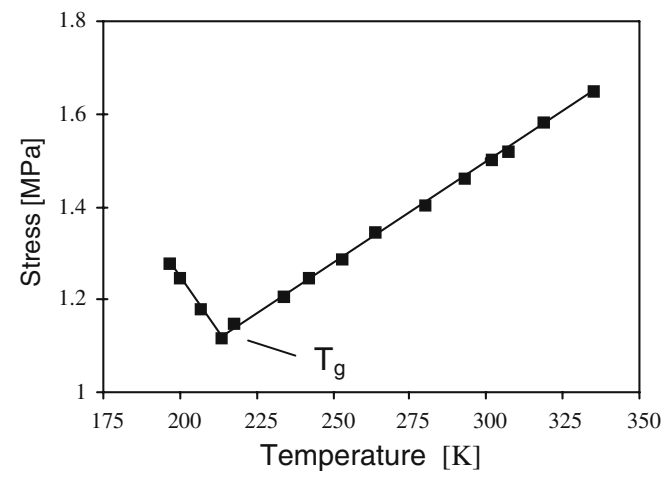

Fig. 1 Variation of stress with temperature for a slightly vulcanized natural rubber band strained to an extension ratio $\lambda=3.5$ (redrawn from data of [7]) 
Bernard Lotz from Strasbourg (in a recent lecture [8] in Lodz) drew the attention to this example of another fundamental discovery, for which at that time the discoverer and the scientific community were not yet ready to see the general significance of the phenomenon, the folding of chains.

Further progress during and after the war For obvious reason progress in the 1940s came predominantly from the USA. Representative for many prominent researchers in this difficult period, three names may be mentioned: Linus Pauling, Hermann Francis Mark and Paul J. Flory.

Linus Pauling (1901-1994) explained the nature of the chemical bond [9] in all its forms (covalent, ionic, unsaturated, aromatic), which laid the foundation to an understanding of the structure and reactions of organic molecules. For this and later important contributions (the $\alpha$ helix as a structural element of proteins), he was awarded in 1954 the first of his two Nobel Prizes, that in Chemistry.

H. F. Mark (1895-1992) arrived in Brooklyn in 1940. Later named Father of Polymer Science, he has impregnated all polymer domains with his creative personality, has organised academic teaching and founded (in 1946) the Journal of Polymer Science.

P.J. Flory (1910-1985) had a widespread industrial experience before he joined (in 1948) Cornell University and started his fundamental work on the Chemistry of polymers and the Statistical thermodynamics of polymer solutions and melts for which he was rewarded with the Nobel Prize in Chemistry in 1974.

Other topics and names in this decade include the state of (crystalline) order, X-ray and spectroscopic techniques of investigation and the thermodynamics of crystallisation and glass transition (associated with names like Bunn, Huggins, Jenckell, Kratky, Krimm, Mandelkern, F.H. Müller, Volkenstein). Mechanical properties were related to molecular structure (e.g. by Eyring, Stavermann, Alfrey and Haward). The rapidly increasing knowledge in macromolecular science is well demonstrated by looking at encyclopaedic reviews of it. In 1947 Staudinger could summarize macromolecular chemistry, physics and biology in a small volume [10] of 150 pages - a few years later four volumes (and almost 3,000 pages) were needed to just describe the physics of high polymers [11] and in 1966 the Encyclopaedia of Polymer Science and Technology [12] came out in 12 volumes.

\section{The discoveries in the 1950s, which completed the foundations of macromolecular science}

The most spectacular development in this period was certainly the elucidation of protein and nucleic acid structures by J. Watson, F. Crick and M. Wilkins, which will not be discussed in this paper (see [1, 2]). As other essential discoveries in this decade, we have to consider the recognition of nature, significance and control of stereoregularity and chain length; the discovery of folded chain laminar crystal morphology and related morphological features and the description of shape and viscoelastic behaviour of chains in liquid and solid state. Following Turner Alfrey [13], we may add the revelation of novel, subtle and significant aspects of fracture mechanisms, craze formation and kinetic theory of strength, subjects which are certainly less fundamental, but have given rise to intense research activities for half a century. It is interesting to note that in this period, where the foundations of macromolecular science had been completed, some major scientific societies have created their polymer divisions (see later).

Stereoregular and ionic polymerization As specified in the "Introduction", one of the aims of macromolecular science is the control of chain configuration and length; this aim was achieved in this decade. In 1953, K. Ziegler (Mühlheim) and G. Natta (Milano) discovered that stereoregular (isotactic or syndiotactic) polymers could be obtained using organometallic catalysts. Both species are crystallisable whereas the formerly produced irregular, atactic species were not. The most important among the many commercial polymers prepared with such catalysts are polyolefins (PE, PP) and ethylene-copolymers. For their discovery, Ziegler and Natta were awarded the Nobel Prize in Chemistry in 1963.

Studying anionic polymerization Szwarc (Syracuse, NY, USA) observed that under special conditions the active carbanions of the growing chains, which were all initiated at the same time, did not recombine, they remained living. Living polymerization resulted in a well-controlled, narrow distribution of chain lengths and also offered the possibility to introduce specific end groups or other monomers leading to block copolymers (as reported by Morawetz [1], the living anions had already been observed in 1936 by Abkin and Medvedev [14] - but once again the time was not yet ripe to fully evaluate its technical prospects). These new polymerization techniques permitted the realization of a group of engineering plastics with improved properties, which Rånby [15] had called the second generation.

Chain folding in polymer crystallisation and the role of chain length Independently from each other, A. Keller [16], E. W. Fischer [17] and P.H. Till [18] (re)discovered [1] by electron diffraction experiments that the axes of long chains in (much thinner, lozenge-shaped single) crystals platelet were directed perpendicular to the major platelet surface, which necessarily meant that they had to 
be folded during crystallisation (as mentioned above, Storkes had communicated the same observation in 1938, but the generality of this phenomenon was not recognized at that time). In the 50 years following the rediscovery, much has been learned about chain folding and Bassett [19] has particularly reviewed the influence of chain length and defects on dynamics and crystal morphology, including the existence of quantized lamellar thicknesses of $n$-alkanes.

A few years after Keller/Fischer/Till, Bernard Cohen painted At This Moment exposed in the Tate Gallery, London, where the author of this paper had discovered it and found that it is a beautiful artistic representation of randomly folded chains [20]. It becomes evident even from the above artistic model that the yield strength of such a material depends mainly on stress transmission by secondary bonds that they are van der Waals solids. Under stress, less than $1 \%$ of the load is borne by primary bonds [20]. However, if the long chains are loaded to only $1 \%$ of their capacity and if such solids show strain hardening (through segmental orientation) even without entanglements, what is then the role of chain length? There are two important groups of parameters, which depend on the length of the constituent chains (Fig. 2):

Static effects associated with chain length:

- Cohesive energy per chain increases; chain length is also the prime parameter which determines the geometry of coiled chains (radius of gyration) and the miscibility and phase behaviour (Flory-Huggins theory)

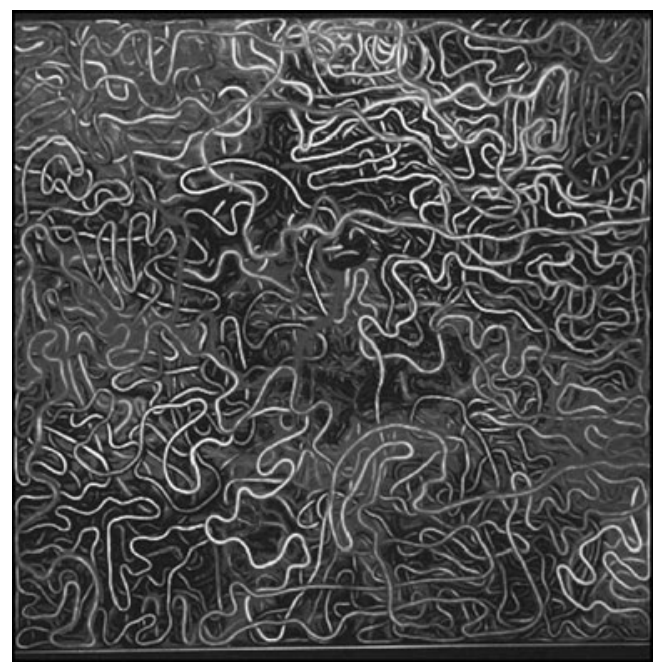

Fig. 2 At This Moment, black-and-white copy of a painting by Bernhard Cohen, 1965, exposed in the Tate Gallery, London; the coloured original is infinitely more impressive; whether coincidental or not, the painting gives an artistic representation of the "structural features" of the amorphous state as discussed in the early sixties: randomly oriented chain segments showing a certain close range order and the presence of chain folds (cited from H. H. Kausch [20])
Dynamic effects:

- The relative number of highly mobile chain ends is reduced.

- Chain length has a strong influence on solution and melt rheology, crystallisation and crystal morphology [19] and through entanglement formation on rubber elastic behaviour and on long-range stress transfer.

These arguments have to be kept in mind when looking at the Bueche/Vincent model of strength.

Shape and viscoelastic behaviour of chains in liquid and solid state Although the behaviour of macromolecular solutions is not subject of this review, it should be mentioned that the notable contributions of Fox and Flory (theta solvent) and of Rouse and Zimm (bead-spring model of a chain, respectively, in free- and non-free draining condition) were also obtained in this period [1].

The WLF equation John D. Ferry's statement (in 1950) that all relaxation mechanisms have the same temperature dependence marks a major breakthrough in the theory of linear viscoelasticity. Together with his collaborators M.L. Williams and R. F. Landel, he derives in 1955 the timetemperature shift equation, which bears their name, the WLF equation [21]:

$\log a_{\mathrm{T}}=-C_{1}\left(T_{\mathrm{r}}-T_{\mathrm{g}}\right) /\left[\left(C_{2}+T-T_{\mathrm{g}}\right)\right]$

where $a_{\mathrm{T}}$ is the dimensionless temperature-dependent shift factor. If as reference temperature $T_{\mathrm{r}}$ the glass transition temperature $T_{\mathrm{g}}$ is chosen, one obtains $C_{1}=17.4, C_{2}=51.6$ [K] (Fig. 3).

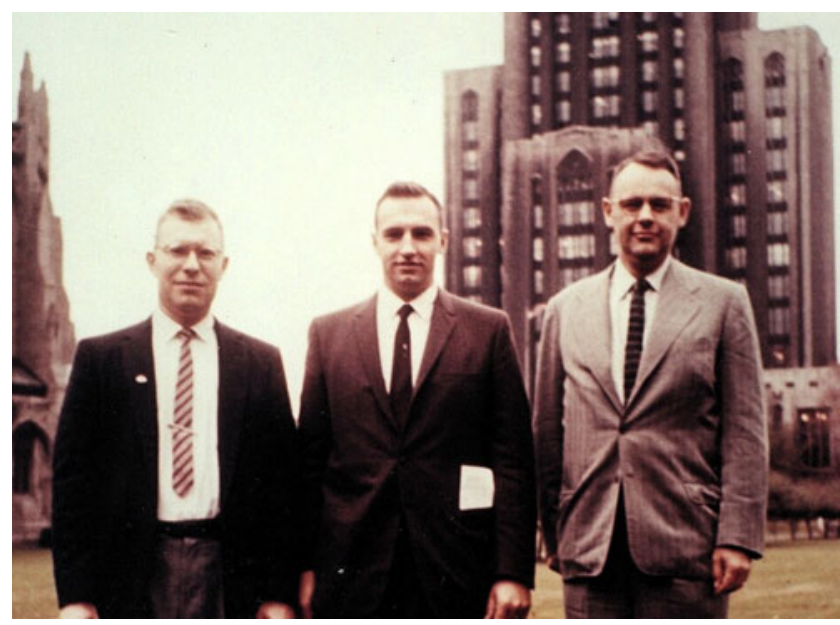

Fig. 3 M.L. Williams, R. F. Landel and J.D. Ferry in Wisconsin at the time of the formulation of the time-temperature shift equation, which bears their name (photo: courtesy Carlisle Landel, Philadelphia) 
The principle of time-temperature shift permits the superposition of data obtained at different temperatures for viscoelastic quantities (e.g. moduli) and thus their extrapolation into otherwise inaccessible regions of time and temperature. What makes the principle particularly valuable for engineering applications is the fact that within the regime of linear viscoelasticity, also mechanical and/or electrical stresses can be included for a stress-timetemperature superposition principle.

Credit must also be given to $\mathrm{H}$. Leaderman for his contributions to the development of the molecular theory of viscoelastic behaviour (including non-linear viscoelasticity) and his account of its early history [22, 23]. A comprehensive mathematical analysis of superposition and extrapolation on the basis of viscoelastic spectra was later given by Tschoegl $[23]^{5}$.

Craze formation The first report on the formation of silvery discontinuities in polymers under tensile stress - called crazes - came from Hsiao and Sauer [24] in 1950. It took almost 20 years before Kambour [25] found out that crazes resemble an open-celled foam with holes and fibrillar polymer elements having a diameter of the order of $20 \mathrm{~nm}$, later Paredes and Fischer reported on the influence of fibrillation stress on fibril diameter, Hull and Döll studied craze profiles and growth histories, Sternstein and Oxborough proposed bi-dimensional stress-bias craze initiation criteria, Kambour that of critical strain and Marshall and Williams that of critical stress intensity factor $K_{\text {Ic }}$ (all referenced in [20]).

Bueche/Vincent model of strength and the kinetic theory of fracture In view of the enormous stiffness of straight chains (Young's moduli of the order of $300 \mathrm{GPa}$ ), it was - and occasionally still is - believed that the chain backbones carry most of the load. This model was comforted by the strong influence of chain length on mechanical properties and by the breakage of chains in fracture experiments (see Fig. 4).

In 1972, Vincent [27] noted that the critical strengths $\sigma_{\mathrm{cr}}$ of non-oriented thermoplastic polymers were linearly correlated with the number $n_{\mathrm{b}}$ of backbone bonds per square nanometre (the critical strength $\sigma_{\mathrm{cr}}$ is defined as the tensile strength of a material at the brittle-ductile transition temperature). From the slope of his diagram, he concluded that each backbone contributes $36.8 \mathrm{MPa}$ to the critical strength, which is much less than $1 \%$ of the strength of a $-\mathrm{C}-\mathrm{C}-$ chain. The perfect correlation between $\sigma_{\mathrm{cr}}$ and $n_{\mathrm{b}}$ is in part due to the fact that

\footnotetext{
${ }^{5}$ Nicholas W. Tschoegl of Caltech, Pasadena, is not only a prominent rheologist but also one of the most fascinating personalities. Born in former Czechoslovakia of Franco-Hungarian parents, married to a polish wife, having lived in Hungary, Italy, Australia and the USA, he speaks 12 languages: a truly global citizen - with a wide span of cultural interests.
}

Fig. 4 In the first models of polymer strength, all load bearing capacity was assigned to the chain segments between cross-linking or entanglement points [26]

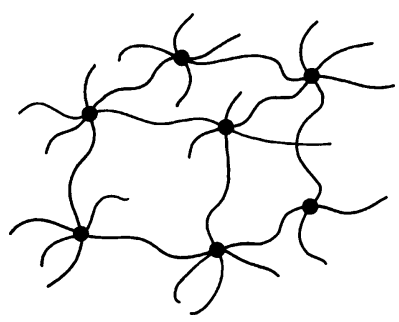

slim backbones (POM, PA, PE) are closer to each other which increases their van der Waals attraction. The relation between tensile strength and density of backbone chains is entirely different, however, if highly oriented fibres are concerned (see that section).

In the late 1930s, Eyring and Tobolsky had derived creep rates and failure times of metals and polymers applying the famous Theory of Rate Processes to secondary bonds. Later, Zhurkov [28] and Bueche [26] interpreted their universal semi-logarithmic relation between time to failure $t_{\mathrm{b}}$ and uniaxial stress $\sigma_{\mathrm{o}}$ as breakage of primary bonds:

$\ln t_{\mathrm{b}} / t_{0}=U_{0}-\gamma \sigma_{0} / R T$

Zhurkov's ideas were supported by his observations of chain scission events and of highly deformed bonds in the intriguing experiments he had developed in the 1960s. Such experiments on chain scission (by ESR) and highly stressed bonds (by IR) were later also done [20] in Sapporo (Sohma), Darmstadt (Becht/Kausch), Salt Lake City (DeVries), London (Andrews), Fukuoka (Takayanagi) and Urbana (Wool). In analysing the number of broken bonds and their kinetics Kausch could show in 1978 [20], that chain scission is the consequence of local straining and not the origin of final failure (even moderately oriented fibres are van der Waals solids).

The above equation correctly predicts the semi-logarithmic decrease of lifetime with stress. However, all morphological details of the stressed sample are comprised in the single parameter $\gamma$. In order to identify the role in deformation and fracture of the nature, length and architecture of the chains, of their degree of orientation and crystallinity, a micromechanical model of the stressed polymer is needed.

\section{The discoveries of the 1950s stimulate research in the 1960s, namely on crystallisation, local motion, molecular orientation and on new applications and improved methods of characterization}

Crystallisation and basic morphological structures Once chain folded crystals had been identified (in 1957) models of crystallisation emerged. The driving force for crystal growth in the model of Lauritzen and Hoffman [29] is the loss of lateral free energy $\gamma_{\mathrm{s}}$ when a stem joins the flat 
surface of a preexisting crystal. The primary crystalline lamellar thickness then depends on the difference between $\gamma_{\mathrm{s}}$ and the free energy $\gamma_{\mathrm{f}}$ of the fold surface. Crystallisation evidently involves first the nucleation of a germ and the diffusion of stems to this site. In most nucleation theories, the initial lamellar thickness depends on the ratio of the fold free surface energy to the energy of fusion. Depending on the material and environmental parameters, crystalline matter grows into single crystals, stacked or radiating lamellae separated by amorphous regions and interconnected by tie molecules. Crystallisation from (dilute) solution leads to single crystals or stacked lamellae [16-19]. Polymer coils in the melt have a much more limited mobility - large-scale segmental displacements during rapid crystallisation are practically excluded. Stamm, Fischer, Dettenmaier and Covert [30] later confirmed by small- and intermediateangle neutron scattering studies of deuterated linear PE chains in a protonated environment that the radius of gyration remains essentially constant upon solidification $[30,31],{ }^{6}$ chains are incorporated into the growing crystal with a minimum of reorganization within the radius of gyration of the coil (solidification model) [30]. Since coils in a melt heavily penetrate each other one finds stems from different coils in each crystallite - and, vice versa, stems from one and the same molecule in different crystallites, which leads to the most-welcome interconnection of crystal lamellae by tie molecules. This important field is comprehensively reviewed by, e.g. Bassett [32, 33] and Wunderlich [34].

Molecular motion and external constraints lead to crystal defects, which were recognized and described shortly after the discovery of chain folding (Reneker [35], later reviewed by van der Werff [36]). Bonart and Hosemann proposed the concept of-defect-rich - paracrystals [37] in order to explain the line shapes in their X-ray diffraction diagrams.

The higher density and better organisation of crystalline matter improves stiffness, yield strength and resistance to environmental stress cracking and fatigue of semicrystalline polymers. M. Takayanagi [38] has developed his instructive two-phase models to predict the effect of the degree of crystallinity on (mechanical) behaviour. Crystalline super-structures (e.g. spherulites or transcrystalline regions) [32-34] will especially influence the deformation and strength of such materials.

Local motion Eyring had considered local jumps in his theory of flow. F.H. Müller [39] ${ }^{7}$ and W. Holzmüller [40] ${ }^{8}$ used the same concept (Platzwechsel) to explain dielectric

\footnotetext{
${ }^{6}$ In this investigation, Dettenmaier et al. [31] found that the time of relaxation of a deformed coil of PMMA at $T_{\mathrm{g}}+10 \mathrm{~K}$ amounts to 32,000 years.

${ }^{7}$ In the 1930s, both F.H. Müller, later in Marburg, and W. Holzmüller, Leipzig, were Ph.D. students of P. Debye in Leipzig.

${ }^{8}$ Ibid
}

and later mechanical relaxation. Such investigations benefitted enormously from the realization (in 1952) of torsion pendulum instruments by Schmieder and Wolf [41]. The improved knowledge of the organisation of chain molecules has led in the 1960 to a larger number of investigations on the molecular origin of energy dissipation observed by temperature-dependent dynamic mechanical (torsion pendulum) and dielectric spectroscopy [42, 43]. By systematically varying the ester-groups in poly(methyl acrylate), Heijboer [43] could associate the $\beta$-relaxation peak of these materials to side group motions. McCrum et al. [42] identified for PMMA the glass transition as origin of the $\alpha$-relaxation peak, and for the sub- $T_{\mathrm{g}}$ peaks, the ester group rotation $(\beta), \alpha$-methyl group rotation $(\gamma)$ and side chain methyl group motions $(\delta)$, respectively. In addition, they could show that the dynamic mechanical and dielectric loss peaks have the same frequency-temperature dependence. For methylene sequences of more than three or four $\left(-\mathrm{CH}_{2}-\right)$ groups, Boyer and Schatzki proposed their famous crankshaft model (rotation about collinear main chain bonds) [43]. With the advent of multi-dimensional nuclear magnetic resonance (NMR) spectroscopy and computer simulation techniques, it became possible to study the nature of molecular motions more precisely and to show that they are not strictly local, but subject to (far-reaching) intra- and inter-molecular cooperativity [44].

Molecular orientation By gradually unravelling a molecular coil, retractive stresses can be increased from those of a rubber - some megapascal - to those of the chain backbone of the order of $10 \mathrm{GPa}$. Whereas a rubber normally recoils, molecular orientation can be fixed in thermoplastics by crystallisation or-in amorphous polymers-by intermolecular van der Waals attraction. This may be desirableas in fibre production or reinforcement through bi-axial orientation - or a damaging effect, if it leads to a loss of structural stability or to birefringence. No wonder that the structural changes occurring during the extension of a thermoplastic polymer - especially of a semi-crystalline one- have attracted scientific and commercial interest for a long time. One of the leading experts in both fields is certainly I. M. Ward, Leeds [45-47]. More will be said later in relation to highly oriented fibres.

New applications The newly available techniques to synthesize long, linear and stereoregular chains were rapidly exploited. Already in 1956, the HOECHST AG started the industrial production of linear high-density polyethylene (HDPE). This highly crystalline and stiff material was well suited for load bearing applications and penetrated rapidly into most branches of industrial production - also favoured by the improved precision and speed of operation of processing machines. In 1958, MANNESMANN AG in 
Duisburg began to extrude light-weight medium pressure HDPE water pipes. ${ }^{9}$

Improved experimental techniques Evidently our understanding of polymer structure and behaviour is intimately related to progress in experimental techniques. As examples, we may mention rheological measurements, infrared and Raman spectroscopy, electron microscopy, NMR spectroscopy and fracture mechanics.

All of the above methods - already known at that time and quite successfully employed - have undergone decisive developments between 1955 and 1965. As we have seen, rheology, science mère of macromolecular science (see Staudinger's work), has been used for polymer characterization from the very beginning (Mark-Houwink equation, melt flow index). In the middle 1950s, automation and improved precision have greatly facilitated rheological investigations. ${ }^{10}$ The latter are part of macromolecular science, and their analysis has always profited from progress in macromolecular physics and has stimulated it in return. The books of Piau/Agassant [48] and of Marrucci/Greco/Ianniruberto [49] are excellent examples of this interaction.

Known since the beginning of the twentieth century [5], IR spectroscopy came into wide use in the middle 1950s to identify the chemical nature of polymers, resins and additives, but also to determine chain tacticity, stiffness and elastic bond deformation and the degree of crystallinity $[1,28,50]$. Later developments-Fourier transform (FT)-IR spectroscopy and Raman microscopy - have further improved these techniques [51].

Another extremely versatile analytical tool, the NMR spectroscopy, had been pioneered by C.P. Slichter [52], following the Nobel prize winning studies of O. Stern, I.I. Rabi, F. Bloch and E.M. Purcell in the 1940s. Nuclear spins such as ${ }^{1} \mathrm{H}$ or ${ }^{13} \mathrm{C}$ exposed to external magnetic fields can be stimulated to resonance absorption of microwave energy; in the liquid state, NMR spectra show distinct lines corresponding to the interaction of the magnetic moments with each other and with their electronic environment; their position-chemical shift—gives information with respect to the molecular configuration and the mobility of the resonating nuclei [52]. In the solid state, the reduced mobility of molecular segments, their fixed arbitrary orientation and their interaction with each other lead to considerable line broadening. Nevertheless, information on,

\footnotetext{
${ }^{9}$ In 1960 , the author was engaged by MANNESMANN to study the mechanisms of thermomechanical aging of HDPE and PVC.

${ }^{10}$ In the early $1950 \mathrm{~s}$, rheometers still had to be read out by hand. Hans Batzer, later Head of Research of the Division Kunststoffe und Additive of Ciba, Basel, had once indicated to the author that during his habilitation work with $\mathrm{H}$. Staudinger in that period, he had to operate manually 50 rheometers, which were running simultaneously.
}

e.g. the amorphous fraction, crystal morphology and annealing treatment can be obtained.

As discussed above, the first electron microscope had already been constructed in 1933 by E. Ruska, initially providing an enlargement by a factor of ten. With considerably improved instruments, crystal structures were successfully studied in the 1950s (see the discovery of chain folding in 1957). The first modern scanning electron microscope (Stereoscan ${ }^{\circledR}$ ) was produced in 1965 . The different forms of electron microscopy have become a powerful tool of structural analysis. A comprehensive review of the different techniques and of the methods of sample preparation has been given by Michler [53].

Fracture mechanics methods were conceived in the 1920 s to quantify the resistance against crack propagation; they had been used with metals for almost 50 years, before it was attempted to apply them to ductile materials. The viscoelastic behaviour and the ease of plastic deformation of polymers heavily influence any measured value of toughness. Max Lea Williams (Pasadena, later Salt Lake City and Pittsburgh, co-founder of the International Congress on Fracture, ICF, in 1965) and J.G. Williams, London, have pioneered Fracture Mechanics of Polymers [54]. Kausch (1978/1987) [20] and Kinloch and Young (1984) [55] have given reviews on the problems, approaches and notable results reported in the first years of its application. The book by J.G. Williams [54] and the recent compilation of Grellmann and Seidler [56] of standardized fracture mechanics methods for polymer characterization are still leading references in this field.

\section{Polymer-related societies and groups}

Scientific progress has at all times benefitted from an exchange of information through pertinent publications, professional associations and the stimulation obtained from personal discussions. Before continuing our walk through another 40 years of the history of macromolecular science, it may be adequate to look back as well as forward on polymerrelated societies and on the dates of their foundation (Table 1).

The given selection shows that most major professional societies have added polymer groups in the period just discussed, between 1951 and the early 1970s. Rubbers were much earlier - they did not have to wait for the theory of rubber elasticity in order to promote industrial needs. It should also be noted that the Kolloid-Gesellschaft and the Society of Rheology were directly founded by newly growing disciplines - and before the concept of macromolecules had been established. For good reason, since it was precisely from these two disciplines that the concept of macromolecules had emerged. 
Table 1 Major scientific associations and year of their foundation

\begin{tabular}{|c|c|c|}
\hline Year of foundation & Society, group or division & Remarks (mother society—if any) \\
\hline 1909 & Rubber Division & American Chemical Society (see [6]) \\
\hline 1921 & International Union of Pure \& Applied Chemistry & $\begin{array}{l}\text { Created to appoint commissions for organic, } \\
\text { inorganic and biochemical nomenclature }\end{array}$ \\
\hline 1922 & Kolloid-Gesellschaft & $\begin{array}{l}\text { The Frankfurt meeting in } 1930 \text { gave birth to } \\
\text { macromolecular science }\end{array}$ \\
\hline 1929 & Society of Rheology & $-{ }^{\mathrm{a}}$ \\
\hline 1944 & Division of High Polymer Physics & American Physical Society \\
\hline 1948 & Fachgruppe Makromolekulare Chemie & Gesellschaft Deutscher Chemiker \\
\hline 1950 & Division of Polymer Chemistry & American Chemical Society (see [57]) \\
\hline $\begin{array}{l}1951 \\
1951\end{array}$ & $\begin{array}{l}\text { Fachausschuss Physik der Hochpolymeren } \\
\text { Society of Polymer Science Japan }\end{array}$ & Deutsche Phys. Gesellschaft \\
\hline 1970 & Groupe français d'études et d'applications des polymers & \\
\hline 1971 & Macromolecular Physics Section & European Physical Society \\
\hline \multirow[t]{3}{*}{1972} & Polymer Physics Group & Royal Society of Chemistry \\
\hline & & With Institute of Physics \\
\hline & $\begin{array}{l}\text { The Macromolecular Group (www.makrogroup.org.uk } \\
\text { (about history) consulted } 30 \text { January 2011) }\end{array}$ & Royal Society of Chemistry \\
\hline 1974 & $\begin{array}{l}\text { L'Associazione Italiana di Scienza e Tecnologia delle } \\
\text { Macromolecole }\end{array}$ & \\
\hline
\end{tabular}

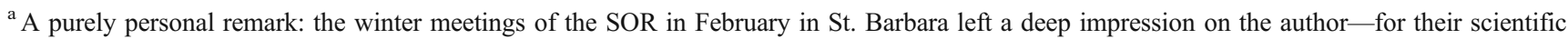
level, their ambiance and because he was permitted to exchange the sub-zero Minneapolis weather for blooming camellias

The Macromolecular Physics Section of the European Physical Society In view of the author's strong involvement with the Macromolecular Physics Section of European Physical Society (EPS), a few words may be said about its role. The rapidly growing number of polymer materials, the research needs for more specialised applications, the gradual introduction of polymer curricula at universities ${ }^{11}$ and the sophisticated methods of analysis had strongly increased the number of polymer scientists in Europe, so that European polymer meetings became viable. The Macromolecular Physics Section of EPS was founded in 1971 under the impulsion of André Kovacs, Strasbourg, Bengt Rånby, Stockholm and E.W. Fischer, Mainz. The latter was elected first Chairman, followed by André Kovacs, (1974), I.M. Ward, Leeds (1977), H.H. Kausch, Lausanne (1981), Andrew Keller, Bristol (1985), H.G. Kilian, Ulm (1988), D. C. Bassett, Reading (1991) and F. J. Balta-Calleja, Madrid (1994). The photograph below shows some of the Chairmen (Fig. 5).

The importance of international cooperation was also strongly underlined and reinforced by the creation and joint

\footnotetext{
${ }^{11}$ In 1971, the - non-industrial-research in polymer physics in the Federal Republic of Germany was for instance done at only 15 institutions (among them seven universities), with a total of just 110 academics. This situation was successfully amended after a Denkschrift [58] of the German Science Foundation DFG had pinpointed this highly dangerous neglect. Only 10 years later, polymer science was taught at most German universities: 32 institutions, mostly with several different laboratories [59].
}

operation of Research Institutions such as CERN (Geneva 1955, a small side activity there was material resistance to particle irradiation), CEA Saclay (Gif-sur-Yvette, 1955, neutron source), DESY (Hamburg, 1959, synchrotron radiation) and Laue-Langevin (Grenoble, 1969, Neutron scattering, synchrotron radiation). In fact, the availability of strong neutron sources in the early 1970s had favoured the application of neutron scattering technique as a new tool to analyse the geometry and dynamics of (deuterated) polymer chains in solution and in solid state (see later).

An important stimulus was also brought about by National Research Institutions and Academies specifically created to do polymer research such as the Centre d'Etude de Physique Macromoléculaire (Strasbourg, 1947), since 1954 Centre de Recherche sur les Macromolécules (now ICS), the Institute of Polymer Science and Technology (Madrid, 1947), the Deutsches Kunststoff-Institut (Darmstadt, 1957), the Institute of Macromolecular Chemistry (ICM; Prague, 1959), ${ }^{12}$ the Centre of Molecular and Macromolecular Studies of the Polish Academy of Sciences (CMMS PAS; Lodz, 1972), ${ }^{13}$ the Instituto de Estructura de la Materia (Madrid, 1976) or the Max Planck-Institut für

\footnotetext{
${ }^{12}$ The ICM was founded by Prof. O. Wichterle following the notable success of the IUPAC Symposium Prague 1957.

${ }^{13}$ The CMMS in Lodz, where the recent IUPAC symposium ICPB 4 had been held, was established on the initiative of Proff. J. Michalski and Marian Kryszewski, who was a distinguished member of the Board of the Macromolecular Section of EPS.
} 


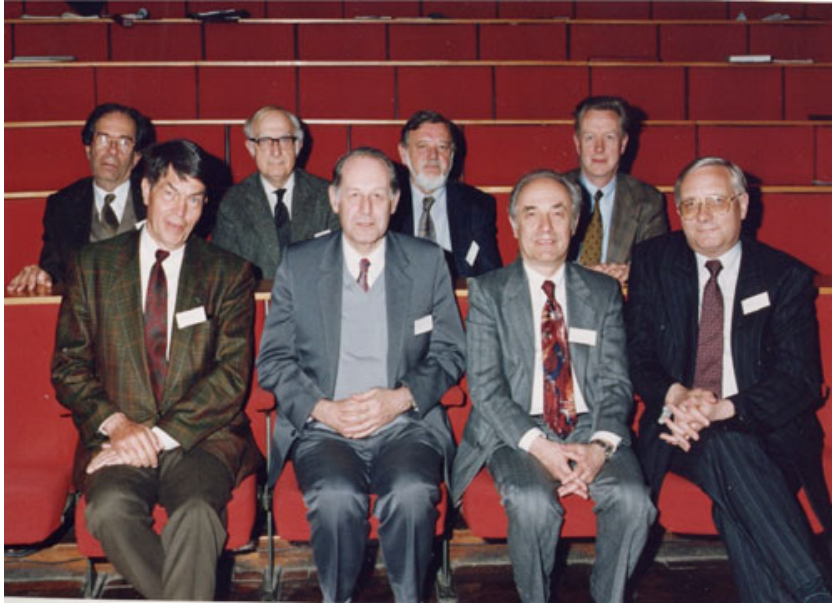

Fig. 5 Photo taken on the occasion of Ian Ward's 65th birthday, April 1993, at the University of Leeds; above A. Keller, A. Argon, E.W. Fischer, L. Monnerie; below H.H. Kausch, I.M. Ward, E. Baer, G. Wegner

Polymerforschung (Mainz, 1983). ${ }^{14}$ Evidently, all of the Material testing and research institutions, some of which were established more than 100 years ago, have wellknown polymer facilities as for instance the Conservatoire des Arts et Metiers (Paris, founded 1794), BAM (Berlin), EMPA (Dübendorf), TGM (Wien), National Bureau of Standards (NBS, now NIST, Gaithersburg) or the Ioffee Physical Technical Institute (at first in Petrograd, then Leningrad, now St. Petersburg).

Much more numerous than the above European research institutions were those in the USA: following the initiative of H. F. Mark, who had founded in 1944 the Institute of Polymer Research at Brooklyn Polytechnic/NY, similar institutions sprang up rapidly; in the 1960s, many of them were well established and particularly attractive for (young) polymer scientists from all over the world for short, longer or even permanent stays (see $[1,6,57]$ ), not to forget, of course, the many powerful industrial research laboratories worldwide.

\section{The 1970s: continued progress through new concepts, materials and methods of characterization}

The past four decades (1930-1970) have laid a solid foundation of macromolecular science and produced a wealth of polymer materials competing in volume with the so much older metals. Nevertheless, important new concepts (reptation), materials (functional polymers, blends, strong fibres) and methods of characterization (neutron scattering, 2D- and 3D-NMR spectroscopy) have been developed in this decade.

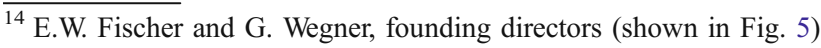

Reptation The presence of entanglements had for a long time prevented the theoretical treatment of self-diffusion in polymer melts or concentrated solutions. P.G. de Gennes [60] solved this problem by introducing (in 1971) the tube concept, the reptational motion of a chain in the tube formed by the lateral obstacles through stems from the same or other chains. De Gennes postulated that the Rousebeads of his model chain experience rapid lateral fluctuations and much slower longitudinal fluctuations, which eventually will result in the Rouse chain moving along its tube with a diffusion constant $D_{\mathrm{c}}=k_{\mathrm{b}} T / N \zeta$ with $k_{\mathrm{b}}$ the Boltzmann constant, $N$ the number of beads and $\zeta$ the molecular friction coefficient. The time needed for the chain to escape from its tube, the reptation time $\tau_{\mathrm{d}}$, then is $L^{2} / D_{\mathrm{c}}$, with $L$ the contour length of the tube. For these Scaling Concepts in Polymer Physics [60] derived from order phenomena in simpler systems, de Gennes was awarded the Nobel Prize in Physics 1991. Later Doi and Edwards [61] extended the reptation concept to the behaviour of a deformed viscoelastic body. This approach has enormously stimulated the theory of viscoelasticity; expressions for diffusion coefficients, zero-shear viscosity and divers moduli and compliances could thus be developed. Graessley [62] has derived several such relations and has compared them with experimental results.

The author has used the reptation concept to explain the kinetics of strength buildup at two surfaces in contact [20, 63]. For this he has studied the rehealing above $T_{\mathrm{g}}$ of broken compact tension specimens (of PMMA and SAN) by measuring the fracture toughness $K_{\text {Ic }}$ of the rehealed specimens as a function of healing time $t_{\mathrm{h}}$. Assuming that new entanglements are formed by chains reptating across the interface and that their number $n$ is proportional to the average curvilinear distance of reptation, $\left(\left\langle\Delta s^{2}>\right)^{1 / 2}\right.$, he obtained

$K_{\mathrm{Ic}}\left(t_{\mathrm{h}}\right) \approx\left(G_{\mathrm{Ic}}\right)^{1 / 2} \approx\left[n\left(t_{\mathrm{h}}\right)\right]^{1 / 2} \approx\left(<\Delta s^{2}>\right)^{1 / 4}=\left(2 D_{\mathrm{c}} t_{\mathrm{h}}\right)^{1 / 4}$.

The predicted dependence of $K_{\text {Ic }}$ on $\left(t_{\mathrm{h}}\right)^{1 / 4}$ was experimentally observed (Fig. 6). The temperature dependence of $D_{\text {c }}$ can be well described by an Arrhenius law with an activation energy of $274 \mathrm{kJmol}^{-1}$. It was estimated that at full healing, when the toughness $K_{\text {Io }}$ of the virgin sample was reached, an average depth of interpenetration $\left(2 D_{\mathrm{c}} t_{\mathrm{h}}\right)^{1 / 2}$ equal to $9.9 \mathrm{~nm}$ had occurred. As the difference in kinetics between the fresh samples and the polished ones show, there is a strong influence of the state of the interface on the rehealing process. The loose structure of broken craze fibrils in experiments 1 to 4 increases the speed of interpenetration, possibly by increasing the number of contact sites or the diffusion constant $D_{\mathrm{c}}$. The many open questions were studied with more sophisticated means in the following decades. 


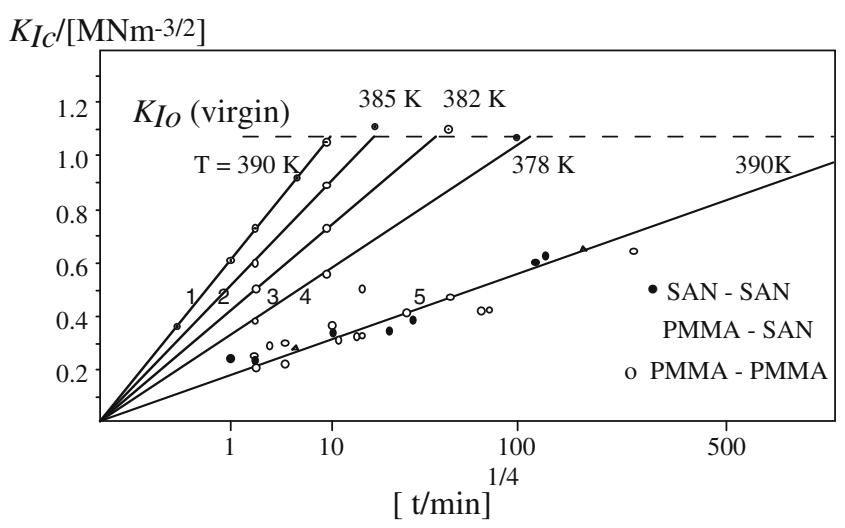

Fig. 6 Kinetics of crack healing in glassy thermoplastics (PMMA, SAN) and at interfaces of compatible polymers PMMA/SAN; curves 1-4 rehealing immediately after fracture, curve 5 rehealing after vacuum drying and polishing (from [20])

In 1998, Schnell and Stamm [64] studied PS interfaces, measuring the width of interpenetration (by neutron reflectivity) and the adhesive forces (using an asymmetric double cantilever beam). Their data are reproduced in Fig. 7. They observe three kinetic regimes designated as: (a) the doubly logarithmic linear increase of adhesive strength $G_{\mathrm{c}}$ at intermediate interpenetration distances $a_{\mathrm{i}}$ was ascribed to the increasing number of newly formed entanglements, (b) for larger interfacial widths there are enough entanglements to permit the full development of a plastic zone at the crack tip in the ACDB specimen as in virgin samples reflected by the jump of $G_{\mathrm{c}}$ to virgin strength. The authors also suggest the existence of a third regime (3) at interpenetration distances smaller than $8 \mathrm{~nm}$, where no stable entanglements have been formed.

High strength fibres Natural fibres have served mankind for more 7,000 years, modified fibres for 120 , fully synthetic

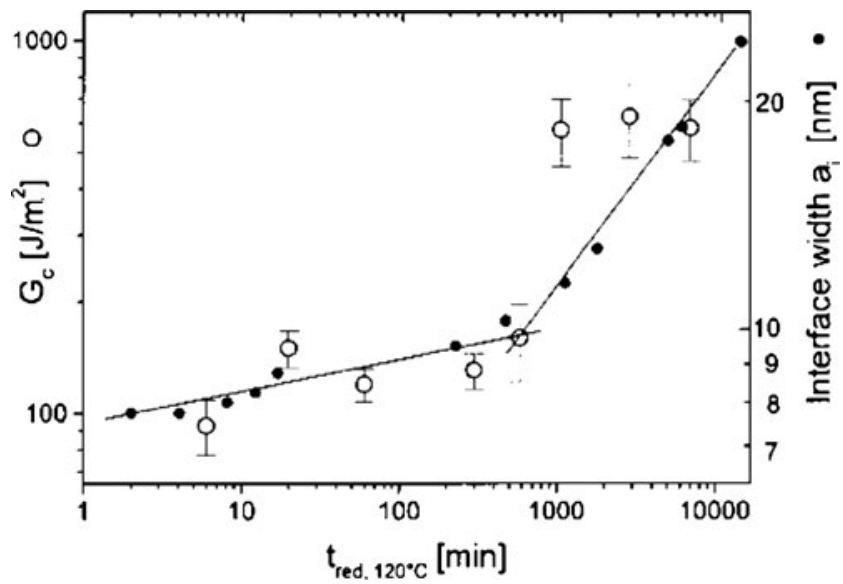

Fig. 7 Double logarithmic plot of adhesive energy $G_{\mathrm{c}}$ of PS/PS $862 \mathrm{k}$ versus the reduced annealing time [64]. For comparison, the interfacial widths obtained by neutron reflectivity for a bilayer PS(D) $752 \mathrm{k} / \mathrm{PS}$ (H) $600 \mathrm{k}$ are also indicated (courtesy M. Stamm) (textile) ones for over 70 years. These fibres had strength values below $1 \mathrm{GPa}$. In the 1970 s, many high strength polymer fibres were developed, with strength values between 2.2 and $5.8 \mathrm{GPa}$, such as the aromatic aramid fibres (Kevlar), carbon fibres, ultra-oriented UHMWPE (Dynema, Spectra) or the aromatic heterocyclic fibres (PBZT, PBZO). An excellent review has been given by Hao Jiang et al. [65]. The structure of these fibres is characterized by an extremely high degree of chain orientation so that the stiffness and strength of the primary bonds come to bear (Fig. 8).

Stiffness and strength of such fibres depend strongly on the number of chain backbones per fibre cross section. Because of the small cross section of a PE chain$0.19 \mathrm{~nm}^{2}$ - UHMWPE is certainly an excellent candidate. Different processing techniques were studied in this decade (Porter, Capaccio, Ward, Smith, Lemstra) [65], and the first commercial UHMWPE fibres appeared (Dynema, Spectra). Unfortunately, the slim configuration of the PE chain makes the fibre prone to creep. Berger and Kausch [66] found that the Sherby-Dorn plot of a Dynema fibre stressed at 1.5 GPa revealed two very distinct regions, an initial region of strains up to $3 \%$, where strain rates decelerate followed by an apparently stationary creep rate of $10^{-6} \mathrm{~s}^{-1}$. Using a high resolution Doppler creep rate meter, Mjasnikova et al. [67] have shown that in similar fibres, the apparently stationary creep rate is in reality a stepwise process - as in fact Mott, Argon and Suter [68] have proposed from atomistic modelling for the plastic deformation of glassy polymers. In view of the many advantages of UHMWPE research still continues, it concerns the influence of catalytic systems on the - quite important - morphology of nascent UHMWPE reactor powders [69], their processability, the optimum number of entanglements per chain [70], the properties of the end product [65, 66, 71], Raman analysis of the local stress distribution on main chain bonds

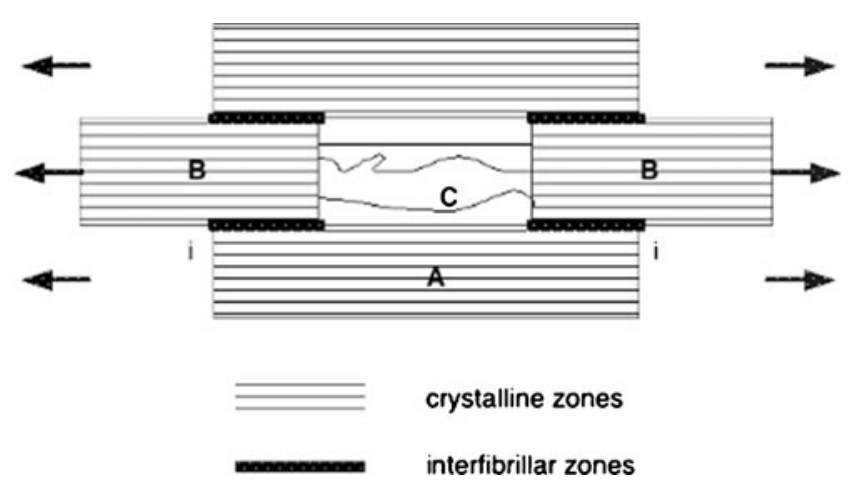

Fig. 8 Schematic structure of an ultra-oriented UHMWPE fibre [66]. Regions A and B are fully crystalline; region $\mathrm{C}$ contains some defects. Slip between $A$ and $B$ leads to load transfer between chain segments. The shown molecular organisation is very close to the one Staudinger had always assumed for macromolecular solids [10] 
[66] or irradiation treatment for the reduction of creep and wear (for improved medical applications) [72].

In this period, several other routes have been followed to obtain high strength fibres: the increased attraction between the stiff backbone chains in lyotropic liquid crystalline polymers (LCP) such as Kevlar or Nomex or between side chain LCPs [73] as well as the aromatic heterocyclic fibres PBZT or PBZO reduce the tendency for slip of the highly oriented chains considerably. The polycrystalline lattices of the different carbon fibres provide the same effect. However, some LCPs and carbon fibres suffer from a limited compressive strength [65].

An interesting approach is offered by high modulus polydiacetylene single crystals [74, 75]. With Young's moduli in the range of 40 to $60 \mathrm{GPa}$, their strengths amount to some 5 to $20 \mathrm{GPa}$. Their remarkable dimensional stability is the absence of creep, even at $100{ }^{\circ} \mathrm{C}$. The high stiffness of such fibres also gives rise to their only disadvantage, a certain sensibility to surface irregularities, which have a crack-like action [75].

New or modified materials, ageing Besides the high strength fibres mentioned above, new polymers with specific thermal or functional properties, the third generation of plastics [15] such as PTFE, PPS, PI, PEEK [76] and electrically conducting or ferroelectric [77] polymers had been brought to the market. The large family of epoxy resins was carefully explored by Batzer and his group at Ciba, who determined the effect of structural elements on the behaviour of the cross-linked network [78]; Pascault et al. [79] have later extensively reviewed the formation of thermosetting networks and their behaviour.

Rather than creating chemically new backbone structures in order to adapt polymer materials for specific applications, it has always been a much easier way to add an appropriate second - or more - phases to an existing matrix and to create filled, blended, toughened, reinforced or conductive polymers. This enormous chapter will not be treated here. A competent reference is the two-volume set Polymer Blends, Formulation and Performance edited by Paul and Bucknall [80]. We should just mention a special group of additives, the stabilizing agents [81], which are added to prevent molecular chain scission as a consequence of degradation reactions at elevated temperatures (during processing or-extended-use) and/or through UV and light irradiation, especially in presence of oxygen and humidity [82]. Such degrading chemical reactions are generally irreversible, susceptible to create damage and to weaken or age the material. As opposed to those external ageing mechanisms, there are also internal, mostly physical ageing mechanisms well detailed by Struik [83] in 1978: loss of free volume, relaxation of entropy and enthalpy, phase separation and/or recrystallisation. At least part of physical ageing is reversible: rejuvenation by heat treatment or deformation [84].

New methods of characterization As mentioned above, the availability of strong neutron sources in the late 1960s had stimulated the application of neutron scattering technique to analyse the geometry of deuterated molecular coils and the dynamics of such chains in polymer solutions and solids. Following the theoretical approaches by Jannink [85] in 1968 and Kirste [86], first experiments were performed in the following years by, e.g. Ballard, Benoit, Cotton, E.W. Fischer, Higgins, Kirste, Schelten and Wignall (referenced in [86-88]). E.W. Fischer and M. Dettenmaier [88] particularly address the question of the structure of amorphous polymers; they stated that the "radii of gyration of single chains in the bulk agree rather well with the values found in U-solution; that segmental orientation correlation does not extend beyond $10 \AA$; and that from the employed scattering methods no evidence could be found for the organisation of chains in the form of bundles or meanderstructures, most experimental results speak in favour of Flory's coil model". Sadler and Keller [89] were looking at the folding of polyethylene chains in single crystals; their experiments were consistent with largely adjacent re-entrant folding. In their book Polymers and Neutron Scattering, Higgins and Benoit [90] give an excellent introduction into this unique method to distinguish a particular physically contrasted molecule within its environment ("as if it were coloured red" remarked later R.S. Stein [91], groundbreaker in UMass Amherst Chemistry and prominent for his work in structural characterization of polymers). To have paved the way of neutron scattering analysis can be considered as another European contribution to macromolecular science.

The improved speed and capacity of computers have offered new possibilities of polymer characterization. One of the most influential new methods created in this period was the multi-dimensional NMR spectroscopy. R. Ernst, Nobel laureate for chemistry in 1991, indicates in his Autobiography [92] that a number of positive coincidences like his long and fruitful experience with VARIAN in Palo Alto, the later meeting with Jean Jeener (1971), who had originally proposed a simple two-pulse sequence that produces, after two-dimensional Fourier transformation, a two-dimensional (2D) spectrum-and, this should be added, a sequence of ingenious inventions by Ernst and his group-led to the development of multi-dimensional spectroscopy inside and outside of his research group.

The applications of 2D- and 3D-NMR are numerous and extremely valuable, since the determination of the interaction between different (marked) atoms permits to analyse molecular order and dynamics such as cooperative rotational motions of groups, segment packing, conformational transitions and/or chain diffusion [93]. 
Other methods, which came to bear in this period, were FT-IR, static SIMS - later improved by time-of-flight mass spectroscopy-deuteron NMR, cross-polarization magic angle spinning NMR, neutron scattering, synchrotron radiation and microhardness testing ${ }^{15}$; the applications of most of these methods have been evaluated in two comprehensive volumes by Zachmann $[96]^{16}$ and the author. Valuable and sensitive methods for the detection of light elements and depth profiling are Rutherford backscattering (RBS) and forward recoiling elastic scattering (FRES) techniques.

\section{The subjects of the 1980s and 1990s. Single-site} polymerization catalysts; micro-mechanics of polymers: from chain segments and surfaces to nano-composites

In the early 1980s, a breakthrough in metallocene catalyst development occurred, which permitted living polymerization of polyethylene up to high molecular weights and with a better control of its architecture [97]. The narrow molar mass distribution typical for single-site catalysts constitutes a definite advantage over the multi-site Ziegler-Natta catalysts. Meanwhile, new single-site catalysts have been found for the synthesis of syndiotactic or isotactic polypropylene. At present, about $85 \%$ of all polyolefins (including reactor blends and block copolymers) are produced that way.

Micro-mechanics The micro-structure even of macroscopically isotropic polymers is mechanically and geometrically highly heterogeneous. Stress and strain concentrations occur, segments reptate, disentangle, change conformation and orientation and they break. Voids, crazes, shear zones and/or cracks are formed. Micro-mechanics has to take into account all of these interacting, strongly rate- and temperature-dependent mechanisms.

Entanglements Looking at the network model represented in Fig. 4, it is intuitively clear that the strength of a rubbery network should increase with the number of entanglements per unit volume, $\nu_{\mathrm{e}}$. The latter quantity is related to the average molecular weight $M_{\mathrm{e}}$ of segments between entanglement points by $\nu_{\mathrm{e}}=\rho N_{\mathrm{A}} / M_{\mathrm{e}}$, where $\rho$ is the polymer density and $N_{\mathrm{A}}$ Avogadro's number. $M_{\mathrm{e}}$ is obtained through

\footnotetext{
15 A more comprehensive treatment is found in [94] and more lately in [95].

${ }^{16}$ Prof. H. G. Zachmann, Hamburg, distinguished colleague and friend, expert in structure analysis by X-ray and synchrotron radiation, left the polymer community and an active, rich and fruitful life prematurely at the age of 64 - only a few hours after having presented a plenary lecture at a polymer meeting in Stresa at the Lago Magiore.
}

$G=N_{\mathrm{A}} \mathrm{RT} / M_{\mathrm{e}}$, where $G$ is the elastic shear modulus of the polymer in the rubber elastic region above the glass transition (or melting) temperature (compare with Fig. 1). In his influential paper, Wu [98] has demonstrated a close correlation between the critical stress for craze initiation and $\nu_{\mathrm{e}}$. Since crazing is frequently the precursor to fracture, the same correlation is observed for the fracture energy or the stress intensity factor $K_{\text {Ic }}$. In Fig. 9 are plotted the critical $K_{\text {Ic }}$ values against $\nu_{\mathrm{e}}$ for a dozen thermoplastics ranging from the brittle, low- $\nu_{\mathrm{e}}$ PS and PMMA to the tough high $-\nu_{\mathrm{e}}$ PC, PE and PEEK.

Disentanglement, slip of segments and elucidation of molecular crazing mechanisms Entanglements provide strength and toughness to a network, as Figs. 6, 7 and 9 clearly show. Vice versa, disentanglement constitutes a damaging mechanism, it weakens a network locally, may give rise to void formation and thus to transfer of stresses to neighbouring chain segments and subsequent crazing. Loss of entanglements is equivalent to loss of local stress transfer, and it may occur through chain scission, disentanglement by forced reptation or disengagement from van der Waals attraction. These mechanisms can be observed with many glassy polymers during craze formation at different temperatures. Figure 10 shows the structure of crazes in MMA-glutarimide resulting from these mechanisms [99].

The nucleation of crazes (at surface or matrix defects, especially in the presence of active environments), their growth through matrix fibrillation and their breakdown have been studied intensively. Reviews have been given frequently [20, 25, 55, 100-105].

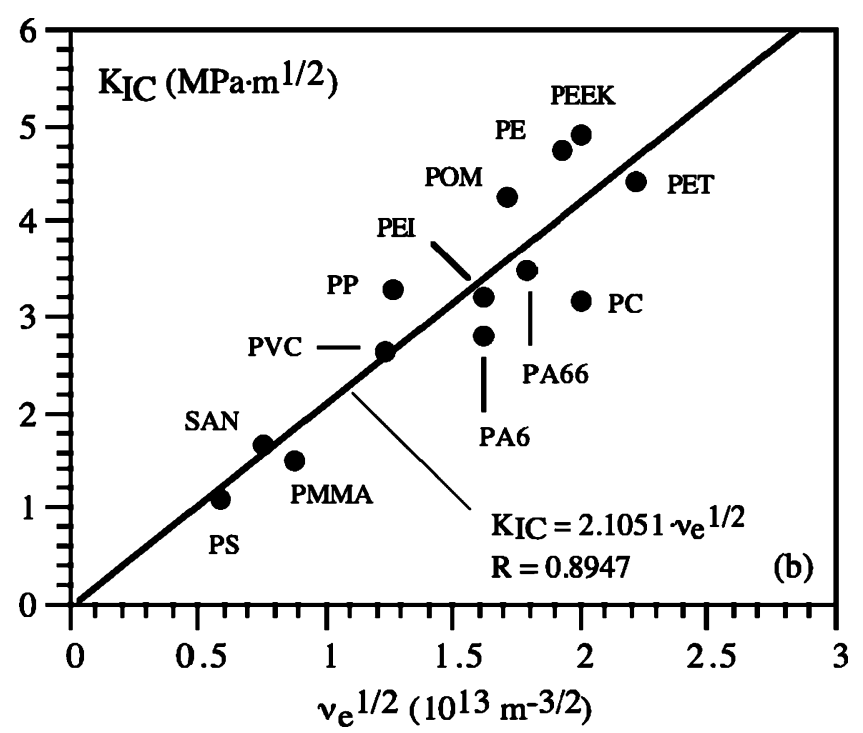

Fig. 9 The stress intensity factor (here noted as $\mathrm{K}_{\mathrm{Ic}}$ ) plotted against the square root of the entanglement density $\nu_{\mathrm{e}}$ (using data from the literature, especially from $\mathrm{Wu}[98]$ ) 


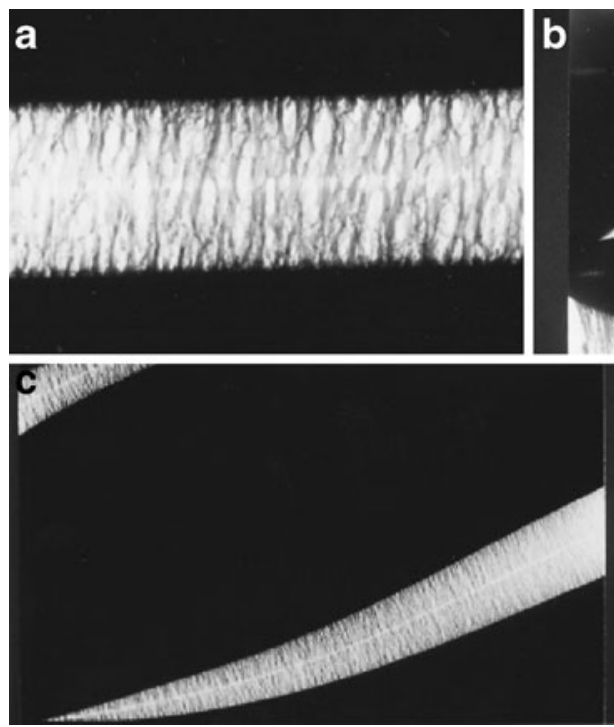

$1 \mu \mathrm{m}$

Fig. 10 Structures of crazes resulting from entanglement loss in samples of MMA-glutarimide stressed at different temperatures: a crazes at $0{ }^{\circ} \mathrm{C}$, initiation through chain scission; b disentanglement through forced reptation at $90{ }^{\circ} \mathrm{C}$; $\mathbf{c}$ almost free pull-out of chains against van der Waals forces at $140{ }^{\circ} \mathrm{C}$ (glass transition of the MMA-

The elementary processes of dynamic stress transfer through chain molecules have been studied by Kramer, ${ }^{17}$ Creton, Char, H.R. Brown and Hui [106, 107]. They made use of the compatibilisation of incompatible polymers through interdiffusion above $T_{\mathrm{g}}$ of block copolymers acting as molecular connectors. After having run a crack along the interface, they traced the depth of interdiffusion of the deuterated blocks by RBS or FRES. From the amount of copolymer placed at the interface, the number of connector chains can be calculated exactly. A review of these very elegant investigations has been given by Creton et al. [107].

From these experiments, the nature of the sample fracture (sharp crack at the interface, crazing of the matrix), the role of the molecular connectors (their surface density $\Sigma$ and the length of both blocks) as well as the molecular failure mechanisms (pull-out of short blocks, scission of well entangled, overloaded chains or matrix failure in case of large $\Sigma$ ) were unambiguously deduced.

Two examples of the role of disentanglement as damage mechanism may be cited: the failure by slow crack growth of HDPE specimens (Fig. 11) and the weak strain hardening of PP in tensile drawing (Fig. 12). The Ziegler-Natta HDPE of the first generation is fairly linear (three to seven ethyl groups per 1,000 carbon atoms) with a relatively broad MW distribution. The characteristic dependence of the time $t$ to

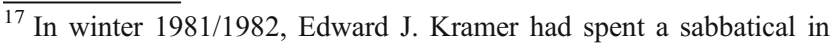
the Polymer Laboratory of the Swiss Federal Institute of Technology (EPFL) in Lausanne. His animated discussions with the author on crazing and interdiffusion have marked some of the subsequent studies in this area in Ithaca as well as in Lausanne
}

glutarimide at $151{ }^{\circ} \mathrm{C}$ ). In the intermediate temperature region (around $50{ }^{\circ} \mathrm{C}$ ), crazes and zones of homogeneous deformation occur together [99]. The so-called mid-rib can be well distinguished in all these structures

failure on the acting stress, $\Delta K \approx t^{1 / 4}$, and the strong effect of increasing MW on $t$ point to the role of disentanglement as principle damage mechanism $[20,108]$. This conclusion

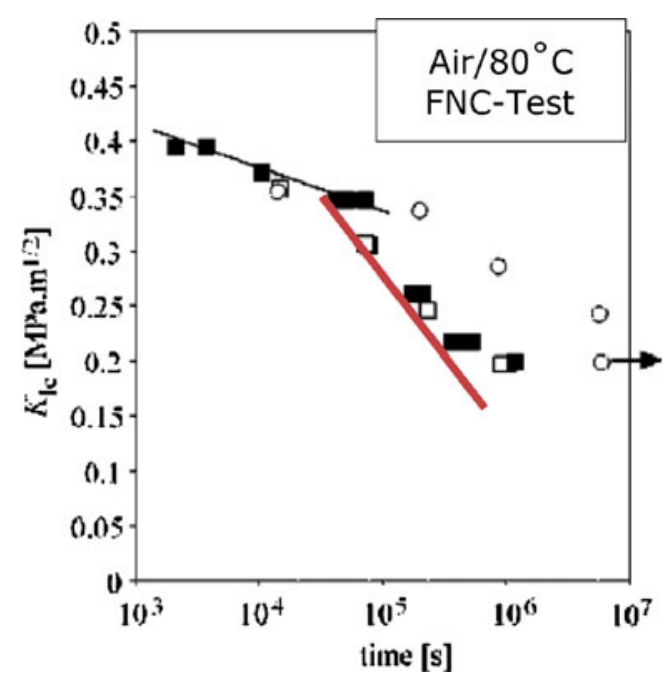

Fig. 11 Time-to-failure of HDPE specimens (using data from Kausch [20] and Plummer [108]). The $K_{\mathrm{Ic}}$ of cylindrical full-notch creep test specimens $(F N C)$ of HDPE are plotted against $\log t$. Filled and open squares are HDPE specimens of the first generation; open circles designate bi-modal specimens of the third generation where the branched units are concentrated towards the ends of the longer chains - an excellent example of the possibilities of the single-site catalysts. The latter PE grades combine high stiffness with good resistance to disentanglement and slow crack growth. Failure occurs by more localized interlamellar disentanglement and cavitation (the superposed heavy line is drawn according to $\Delta K \approx t^{1 / 4}$, a slope which points to disentanglement as the dominant molecular failure mechanisms $[63,108])$ 


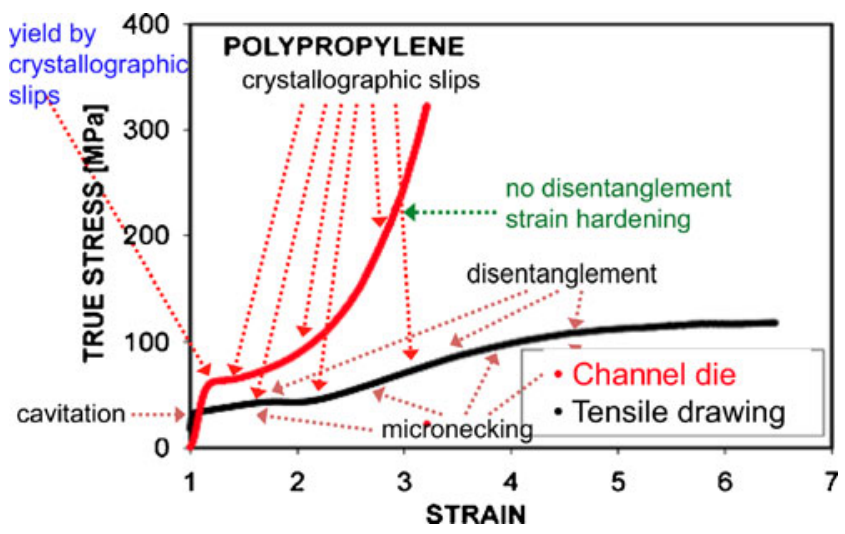

Fig. 12 Although rheologically similar, the two deformation histories are quite different beyond the yield point: In tensile drawing, local positive three-dimensional stresses favour disentanglement, which limits strain hardening; on the other hand, disentanglement is prohibited in compressive channel-die deformation leading to important strain hardening (courtesy A. Galeski [109])

was reinforced by the finding of Norman Brown et al. [110] that the time to failure depends strongly on the density of butyl-branches in polyethylene-hexene copolymers: The presence of small lateral groups reduces the thickness of the crystalline lamellae, increases the number of tie molecules and hinders disentanglement. An even better result is obtained, if the lateral groups are concentrated at the ends of longer chains in bi-modular MW distributions [108]. The realization of these resins of the third generation by singlesite catalysts is in fact an excellent example of the fruitful cooperation of knowledgeable physicists (in demand of a particular chain architecture) with experienced chemists (who can realize them).

The second example is due to Pawlak and Galeski [109], who have compared the behaviour of PP samples deformed in two rheologically similar ways: by drawing in uniaxial tension and by bi-axial compression in a rectangular channel die. The absence of important strain hardening as observed in uniaxial tension is a convincing evidence of the damaging role of disentanglement possible in this mode of elongation - and suppressed in compression (Fig. 12).

Chain dynamics The manifestations of polymer mobility have been known from the very beginning of history, but it was only after the recognition of the macromolecular nature of polymer chains that pertinent experiments and theoretical models were conceived. Thus, the first molecular interpretations of creep and flow (Eyring, Mark-Houwink) and of the glass transition (Simon, Tamman, Ferry and Parks, Fox and Flory) were already given in the 1930s and 1940s (reviewed by Morawetz [1]). The descriptions of chain relaxation, local motion, reptation and crazing followed in subsequent decades and have been cited above. In the period discussed now (the 1980s and 1990s), many investigations concern the close correlation between toughness and molecular relaxations, especially with the mechanical $\beta$-relaxation peak. The intrinsic mobility of backbone chains and their cooperation with neighbouring atoms or groups is a prerequisite to rapidly dissipate elastic energy in regions of high stress concentration and thus to avoid local failure be it through chain scission or crack initiation $[20,111,112]$. Halary et al. give a detailed analysis of the intra- and inter-molecular cooperativity of molecular motions and of their effect on mechanical properties $[44,111,112]$.

Computer simulation techniques have become an important tool [113] to study molecular packing, dynamics and deformation mechanisms (and thus their cooperativity). As an example, we cite the investigation of Hutnik et al. [114], who have shown that a simple phenyl ring flip in a BPAPC molecule has far-reaching and dominant inter-molecular effects.

Fatigue behaviour The viscoelastic response of polymer materials to cyclic — or any other kind of repetitive loading leads to a hysteresis of the stress $(S)$-strain curve, to work done on the specimen and possibly to damage, which increases with stress amplitude and number $\mathrm{N}$ of load cycles. All this is known since - exactly 100 years agoBasquin had plotted Wöhler's endurance data in form of the $S N$ or Wöhler curve. In his rule, Paris substituted some 50 years later stress range by $\Delta K_{\mathrm{I}}$ the amplitude of the stress intensity factor. Herzberg/Manson [115] and Suresh [116] have given pertinent reviews on fatigue behaviour of plastics. In the decades discussed here, the micro-mechanics of fatigue crack propagation has been elucidated. Sauer and Chen [117] have pointed to the importance of compressive stresses and indicated that after rapid strain softening an extended period of gradual increase in hysteresis width follows until crazing occurs (in the studied two-phase glassy polymers). Crazing dramatically increases the energy absorbed and leads to failure within relatively few additional cycles. Pruitt [118] has shown convincingly how fatigue failure in pure compression can occur, Takemori [119] found the epsilon crack tip plastic zones; their appearance led to the interesting phenomenon that an increase in load level can increase the number of cycles to rupture. It is also particularly noteworthy that in fatigue the presence of long chains (high level of $M_{\mathrm{w}}$ ) is about as important as the absence of short chains (narrow molecular weight distribution, Altstädt [120]).

Effects of extensional flow and/or high rate of loading The investigation of the flow of polymers in solution has helped to give birth to the notion of macromolecules. Most chapters of the standard reference [1] on the history of polymer science up to 1960 are devoted to the liquid state. 
So what is new in this field? One domain, which has received particular attention in this decade, was the extensional flow of polymer melts. In extensional flow, the entanglements engaged by longer chains or between longchain branches lead to the orientation and stretching of segments, which increase the flow stress to higher values than predicted by the measured shear viscosity. Many processing flows are extensional rather than shear in nature, especially fibre spinning and blow moulding [121]. Considerable credit goes to J. Meissner, first at BASF in Ludwigshafen, since 1974 at ETH Zürich, for the development of sophisticated experimental techniques to study linear, equi-bi-axial and planar extensional flow of elastomers and polymer melts [122]. The extensional viscosity data thus obtained were indispensable for the correct calculation of melt flow during processing. Fundamental aspects of crystallisation and structure formation during processing have recently been treated by Janeschitz-Kriegl [123].

A related domain concerns the investigation of the dynamics of flexible polymer chains in solution, especially the stretching of molecular coils in strong elongational flow [124]. The coil-stretch transition at a (first) critical elongational flow rate was predicted by de Gennes in 1974, in elegant experiments demonstrated by Keller and his group in 1985 and by Nguyen and Kausch in 1986, and virtually seen by direct imaging of single molecules by a fluorescent measurement technique by $\mathrm{Chu}$ and collaborators in 1997 (Steven Chu received the Nobel Prize in physics in 1997 for his work to cool and trap atoms with laser light). Nguyen and Kausch also studied chain degradation in contracting elongational flow and found that scission occurred exactly in the middle of the fully stretched chains at a second critical elongational flow rate (all references in [124]).

The major consequence of the application of high loading rates to (thermoplastic) solids - as it occurs in impact fracture $[20,54,55,125,126]$ - logically resides in the fact that fast mechanisms (chain scission, cavitation) are favoured over slow mechanisms (segmental slip, crazing, creep). At still higher rates, inertia forces become effective. The experimental observation of high rate fracture and its theoretical and fracture mechanical evaluation had been especially furthered by the group of $\mathrm{K}$. Takahashi at Kyushu University [126].

Surfaces, interfaces, thin films and membranes The organisation and dynamics of molecules is sensitive to material boundaries such as surfaces, interfaces, membranes (important tool for water desalination) or thin films [127-130]. Several new techniques for their investigation became available in the 1980s: the scanning near-field optical microscopy, the atomic force microscopy (developed out of the scanning tunnelling microscope both invented by G. Binnig and H. Rohrer, who received the Nobel Prize in Physics in 1986), X-ray and neutron reflection methods and ion-beam methods [128]. Out of the huge body of surfaceand thin film-related investigations, only two examples will be cited. Thus, the higher mobility of segments in a surface region leads to a depression of $T_{\mathrm{g}}$ (of between 10 and $70 \mathrm{~K}$ [127-129] for different free-standing films). The opposite phenomenon, an increase of $T_{\mathrm{g}}$, is expected for a polymer in contact with a high-energy substrate. Rittigstein et al. [129] have reported an increase of up to $20 \mathrm{~K}$ for PMMA in contact with $\mathrm{SiO}_{2}$; they had used the elegant method to determine $T_{\mathrm{g}}$ by the temperature-dependent change in fluorescence intensity of an appropriate dye. A very special form of thin layers are the stacks of thousands of thin film layers produced by the Baer-Hiltner method of layermultiplying co-extrusion [130], which permits to create engineering microstructures with unique and graded electrical, mechanical, barrier and optical properties.

Micro-mechanics of nano-composites The nano generally refers to the dimensions of the layered or particulate mineral fillers (such as $\mathrm{SiO}_{2}, \mathrm{TiO}_{2}, \mathrm{CaCO}_{3}, \mathrm{Al}_{2} \mathrm{O}_{3}$ or $\mathrm{CdS}$ ), carbon nano-tubes or nano-fibres (or, more recently of graphene, one-atom thick planar sheets of sp2-bonded carbon atoms), electro-spun fibres or of core-shell rubber particles [131]. Evidently, the matrix properties of nanocomposites (and blends [80]) are also important and subject to development (see the comments above on single-site metallocene catalysts). Nano-foams must also be mentioned in this respect. Foaming of multiphase blends seems a promising approach to satisfy the steadily growing demand for cellular materials with enhanced properties [132]. The small size and the large - and frequently active - total surface area of nano-particles or voids give rise to specific properties in quite different fields: increase in mechanical strength and toughness (through well-distributed stress concentrations at filler/matrix interfaces, voiding at high stress level, fibrillation and toughening through the plastic yielding of thin ligaments of basically brittle polymers), improvement of fire resistance and barrier properties. Particulate fillers are employed in thermoplastic [131] as well as in thermosetting [79] or elastomeric [133] matrices. Specific failure mechanisms in particulate filled crosslinked resins are crack bridging and crack pinning. Coreshell nano-fillers enhance shear yielding through their cavitation, and they also give rise to a specific toughening mechanism, the formation of croids, first observed by Sue [134]. Sue had noticed that at a stress concentration site in rubber-modified resins, craze-like lines of voided rubber particles appeared, which indicate that the voiding of a first rubber particle favours the voiding of subsequent ones along lines of maximum stress. 
Reinforcing fillers in rubbers have been employed for more than 100 years (carbon black) [1]. As the foundation of the Rubber Division of ACS as early as 1909 shows, there was an immediate and continuous interest to study the influence of the many additives used in the formulation of rubbers on the structure and behaviour of the resulting network $[1,6]$. Since about 1990, silica fillers are widely used in car tires (M. Daniel from MICHELIN [133] has reported that the use of silica fillers in green tires had helped to reduce the rolling resistance to $1 / 3$ of its value in the year 1900).

\section{The twenty-first century: nano-bio-self}

Looking at the wide spectrum of topics in the literature and at scientific polymer meetings, one realizes that research and innovation still continue in all domains of polymer science: The notable (and little changed) research objectives are to explore new synthetic methodologies including the use of monomers from bio-resources, to identify and improve the micro-structure and mechanical and other physical properties, as well as processing and recycling of polymer materials adapted to the increased requirements in the fields of primary human necessities and comfort: clean water, $\left(\right.$ solar $\left.{ }^{18}\right)$ energy, medical and functional applications, transportation, packaging and the respect of environment (in the future a main challenge will be to derive chemicals from $\mathrm{CO}_{2}$ and bio-mass rather than from crude oil [135]).

Synthetic methodologies Enormous progress had been achieved in the past decade in living (single-site) catalysts [97]. Fetters et al. [136] review the large variety of specific polymers thus obtained and frequently used as model polymers. Nevertheless, work on synthetic methodologies has continued to improve the activity, stability and selectivity of catalysts; Hotta et al. [137] report on advances in synthesis and macromolecular design of semi-crystalline thermoplastic elastomeric polyolefins. A new process, termed chain shuttling polymerization, uses the exchange of growing blocks between different catalysts in presence of a chain shuttling agent, such as a metal alkyl complex that facilitates this transfer [138]. The authors claim that "the resulting statistical multiblock architecture with its distribution of block lengths and number of blocks per chain, is not easily accessible by any other means and leads to excellent elastomeric properties at temperatures far higher than traditional ethylene-based elastomers" [138]. Thermoplastic

\footnotetext{
${ }^{18}$ Fredrickson [135]: "In order to satisfy the need in energy of the 12 billion people expected to live on earth in 2050 mankind has to construct every day for the next 50 years one 1-GW nuclear power plant - or to revert to solar energy as the only feasible solution."
}

elastomer block copolymers are known for 50 years-as for instance $\operatorname{Kraton}^{\circledR}$ [139] - their phase behaviour and structure has been intensively investigated subsequently [140]. Notwithstanding their age, block copolymers are still today a versatile system to study the effect of molecular parameters on nano-pattern evolution [141] and of their response to mechanical stimuli.

New transition metal olefin catalysts have been employed by R. H. Grubbs in studying metathesis reactions; he has made them one of organic chemistry's most important reactions. For this invention, R.H. Grubb - together with R. R. Schrock and Y. Chauvin - was awarded the Nobel Prize in Chemistry in 2005 (see Nobel Prizes/Chemistry/Laureates/ 2005). But even well-established techniques can be further developed, the oil-in-oil emulsion polymerization technique has permitted the formation of polymer nano-particles [142]. In concluding the discussion on the recent developments in synthetic methodologies, we may refer to (computer-controlled) automated parallel syntheses, which are helpful to rapidly identify optimum synthesis parameters [143].

Structure and properties Besides the described research efforts to design new materials at the molecular level in order to predict and control its nano-scale organisation, a second important field concerns the modification-especially with nano-particles - which is opening up pathways for engineering of flexible composites that exhibit advantageous electrical, optical or mechanical properties [131, 144]. Recent advances also revealed routes to exploit both enthalpic and entropic interactions so as to direct the spatial distribution of nano-particles and thereby control the macroscopic performance of the material. For example, by tailoring the particle coating and size, researchers have created self-healing materials for improved sustainability and self-corralling rods for photovoltaic applications. Another challenge for future studies is to create hierarchically structured composites in which each sub-layer contributes a distinct function to yield a mechanically integrated, multifunctional and/or graded material [130, 144].

In all the above cases, the classical mechanical properties - strength, toughness, resistance to degradation and wear-are still of large importance-even for functional objects like contact lenses or solar cells. Although polymers in electronics and optoelectronics are not included in this review, it should at least be mentioned that important progress has been made in this area, as the Nobel Prize in Chemistry, awarded in 2000 to Heeger, McDiarmid and Shirakawa for the discovery and development of conjugated, conductive polymers, testifies (see Nobel Prizes/Chemistry/Laureates/2000). It has to be expected that conductive macromolecules will face competition from small organic molecules, but 
because polymer films can be deposited by solvent coating techniques, polymers are likely to have some place in low cost, large area devices. Three application areas are of particular interest: conjugated polymer light emitting diodes, conjugated polymer field transistors and conjugated polymer/fullerene blends for photovoltaic applications. ${ }^{19}$

So far we have mainly discussed the innovative composition of the employed polymer systems [145], but it should be noted that also the methods of processing have been greatly improved (in fact, the degree of automation and the increased precision, reliability and speed of operation obtained through simulation of flow and heat transfer and through the use of modern equipment are often more important for the performance-and the commercial success - of a product than its cleverly designed micro-structure).

The third field of strong current research interests are biologically inspired polymers; they play a major role in self-sustaining materials technology and in their application within the human body. In a recent article, Mülhaupt [146] pays respect to Staudinger and Ringsdorff for their pioneering advances in this domain. Inert biocompatible polymers are requested to have no negative reaction in the body and thus elicit no chronic inflammatory response in the body. Usually these polymers (such as UHMWPE) are designed to offer structural integrity for a decade or more [147]. Inert coatings help to improve compatibility and wear behaviour (e.g. for total hip joint replacements) [148]. Bio-resorbable polymers (such as PLA and PGA or its derivatives) are used where the polymer is to be metabolized by the body, and they are commonly employed as sutures, suture anchors and drug delivery vehicles. A promising application for the treatment of coronary artery disease, drug eluting bio-resorbable vascular scaffolds, was recently announced by Abbott's (http://www.abbott.com/PressRelease/2011 Jan10.htm). ${ }^{20}$

Bioactive polymers are designed to purposefully elicit a proactive response in the body or to prevent a negative reaction. As examples, we may cite the modification of (polyethylene) substrates with bio-selective or non-fouling, bioactive poly(poly[ethylene glycol] methacrylate) brushes $[149,150]$ or the seeding with cells to encourage tissue growth or in-growth or the realization of this function by mechanical means using porous polymers that encourage tissue in-growth [147].

\footnotetext{
${ }^{19}$ E.J. Kramer, personal communication 2011

${ }^{20}$ A BVS device will be commercialized by Abbott $\hat{s}^{\prime}$ under the brand name ABSORB ${ }^{\mathrm{TM}}$. The BVS device restores blood flow by opening a clogged vessel and providing support to the vessel until the device dissolves within approximately 2 years, leaving patients with a treated vessel free of a permanent metallic implant.
}

A high degree of bio-compatibility is expected from conjugates between peptide/protein-building blocks and synthetic polymer segments. In a recent review, Klok [151] outlines the Quo Vadis of this technique. Conjugates are known since the 1950s, when they were employed in enzyme-mediated drug release. Later their pharmacokinetic action was used in antitumor research [151]. Klok gives an overview on the different synthetic approaches; over the past decade, they have led to impressive advances, although possible applications as bio-molecular drugs or bioactive hybrid hydrogels that can aid in wound healing and tissue regeneration are not yet fully explored [151].

In résumé, one is hoping to develop functional soft matter, self-assembling, communicating with its environment and perhaps selectively stimulating chemical reactions, including self-healing of damaged sites [149-152]. The guideline of this review has been to trace the history of the concept of macromolecules and of the importance of main chain backbones. One of the later applications of highly oriented chains are found in self-reinforced thermoplastics: strong fibres embedded in a matrix of the same material in order to combine strength and toughness with the ease of recycling a chemically uniform material [152].

At the end of this walk through 80 years of macromolecular-or now polymer-science, the author readily admits that there are many other themes, which he hasfor lack of space or personal experience-hardly mentioned, such as optically or electrically active-piezo- or pyro-electric — materials, shape-memory or self-assembling, purpose-oriented polymers. In any event, this review is not meant to be exhaustive; the cited examples should just illustrate where in history and in what fields progress was achieved, progress to which the whole scientific community and not only the referenced authors have contributed.

Acknowledgements The author is highly indebted to A. Galeski for his suggestion to talk about this fascinating subject at the IUPACMeeting in Lodz and for his help and hospitality as Conference Chairman. The author is also grateful to V. Altstaedt, F.J. Balta-Calleja, D.C. Bassett, E.W. Fischer, A. Galeski, J.L. Halary, H.A. Klok, E.J. Kramer, C. Landel, B. Lotz, G.H. Michler, L. Myasnikova, C.J.G. Plummer, L. Pruitt and M. Stamm for extended discussions and for having made available instructive documents.

\section{References}

1. Morawetz H (1985) Polymers, the origins and growth of a science. Wiley, New York

2. Mark HFA (1985) Century of polymer science and technology. ACS Symp Ser 285:3

3. Gäth R (1985) In: Glenz W (ed) Kunststoffe-ein Werkstoff macht Karriere. Hanser, München, p 33

4. Priesner C, Staudinger H, Mark H, Meyer KH (1980) Thesen zur Größe und Struktur der Makromoleküle. Verlag Chemie, Weinheim 
5. Coblentz WW (2011) wikipedia.org, consulted Jan 2011

6. Morton M, Kelley FN (1989) Vignettes from the International Rubber Science Hall of Fame (1958-1988). ACS Rubber Division, Akron

7. Meyer KH, Ferri C (1935) Helv Chim Acta 18:570

8. Lotz B (1753) Refers at the 4th Int. Conf. on Polymer Behaviour, Lodz, 2010, to K.H. Storkes, JACS, 1938

9. Pauling L (1939) The nature of the chemical bond. Cornell University Press, Ithaca

10. Staudinger H (1947) Makromolekulare Chemie und Biologie. Wepf\& Co, Basel

11. Stuart HA (1955) Die Physik der Hochpolymeren. Springer, Berlin

12. Mark HF, Gaylord NG, Bikales NM (eds) (1966) Encyclopaedia of polymer science and technology. Wiley Interscience, New York

13. Alfrey T (1973) Deformation and fracture of high polymers. In: Kausch HH, Hassell JA, Jaffee RI (eds) Battelle Institute Materials Science Colloquia. Plenum, New York, p 22

14. Abkin A, Medvedev S (1936) Trans Faraday Soc 32:286

15. Rånby B (1996) Macromolecular concept and strategy for humanity in science, technology and industry. Springer, Berlin, p 30

16. Keller A (1957) Phil Mag 2:21

17. Fischer EWZ (1957) Naturforsch 12a:753

18. Till PHJ (1957) Polym Sci 24:301

19. Bassett DC (2007) Polymer 48:3384

20. Kausch HH (1978/1987) Polymer fracture. Springer, Heidelberg

21. Ferry JD (1980) Viscoelastic properties of polymers. Wiley, New York

22. Leaderman H (1955) J Polymer Science 16:261

23. Tschoegl NW (1989) The phenomenological theory of linear viscoelastic behavior. Springer, Berlin

24. Hsiao CC, Sauer JA (1950) J Appl Phys 21:1071

25. Kambour RP (1973) J Polymer Sci D 7:1

26. Bueche F (1959) Rubber Chem Techn 32:1269

27. Vincent PI (1972) Polymer 13:557

28. Zhurkov SN, Narzulleyev BN (1953) Zhur Phys Techn 23:1677

29. Lauritzen JI Jr, Hoffman JD (1957) J Res Natl Bur Stand 1960 (64A):73

30. Stamm M, Fischer EW, Dettenmaier M, Convert P (1979) Disc Faraday Soc 68:263

31. Dettenmaier M, Maconnachie A, Higgins JS, Kausch HH, Nguyen TQ (1986) Macromolecules 19:773

32. Bassett DC (ed) (1982) Developments in crystalline polymers. Applied Sciences, London, p 115

33. Bassett DC (2007) Morphology, in encyclopedia of polymer science and technology. Wiley, New York

34. Wunderlich B (1973) Macromolecular physics, vol 1. Academic, New York

35. Reneker DH (1962) J Pol Sci 59:39

36. Van der Werff H, Van Duynen PT, Pennings AJ (1990) Macromolecules 23:2935

37. Bonart R, Hosemann R (1962) Kolloid-Z Z Polymere 186:16

38. Takayanagi M, Imada K (1966) J Polymer Sci C 15:263

39. Müller FH, Engelter A, Kolloid ZZ (1957) Polymere 152:15

40. Holzmüller W (1954) Z Phys Chem 203:163

41. Schmieder K, Wolf K (1952) Kolloid-Z 127:65

42. McCrum NG, Read BE, Williams G (1967) Anelastic and dielectric effects in polymeric solids. Wiley, London

43. Haward RN (1973) The physics of glassy polymers. Appl Sci Publ, London

44. Halary JL, Lauprêtre F (2006) De la macromolécule aux matériaux polymères. Belin, Paris, p 247, will be published in English as: Polymer materials: macroscopic properties and molecular interpretations, Wiley, Hoboken 2011
45. Ward IM (1983) Mechanical properties of solid polymers. Wiley, New York

46. Ward IM (1975) Structure and properties of oriented polymers Wiley, New York

47. Ward IM (2004) Plastics. Rubbers and Composites 33:189

48. Piau J-M, Agassant J-F (eds) (1996) Rheology for polymer melt processing. Elsevier, San Diego

49. Marrucci G, Greco F, Ianniruberto G (1999) Rheology of polymer melts and concentrated solutions. Elsevier Science, Ireland

50. Krimm S (1960) Adv Polymer Sci 2:51

51. Koenig JL (2001) Infrared and Raman spectroscopy of polymers. RAPRA Techn, Shawbury

52. Slichter CP (1978) Principles of magnetic resonance. Springer, Berlin

53. Michler GH (2008) Electron microscopy of polymers. Springer, Berlin

54. Williams JG (1984) Fracture mechanics of polymers. Ellis Horwood, Chichester

55. Kinloch AJ, Young RJ (1983) Fracture behaviour of polymers. Applied Science, London

56. Grellmann W, Seidler S (eds) (2001) Deformation and fracture behaviour of polymers. Springer, Berlin

57. Ulrich RD (ed) (1978) Contemporary topics in polymer science, vol 1. Plenum, New York

58. Forschungsgemeinschaft D (1971) Physik der Polymeren. Denkschrift, Deutsche Forschungsgemeinschaft, Bonn

59. European Science Foundation (1981) Polymer research in Europe, inventory. European Science Foundation, Strasbourg

60. de Gennes PG (1979) Scaling concepts in polymer physics. Cornell Univ Press, Ithaca

61. Doi M, Edwards S (1986) The theory of polymer dynamics. Oxford Univ Press, Oxford

62. Graessley WW (1980) J Polymer Sci: Polymer Physics Edition $18: 27$

63. Jud K, Kausch HH (1979) Polym Bull 1:697

64. Schnell R, Stamm M, Creton C (1998) Macromolecules 31:2284

65. Hao Jiang, Adams WW, Eby RK (1993) Materials Science and Technology. In: Kahrn RW, Haasen P, Kramer EJ (eds) Structure and properties of polymers, vol 12. Verlag Chemie, Weinheim, p 597

66. Berger L, Kausch HH, Plummer CJG (2003) Polymer 44:587

67. Myasnikova L, Marichin VA, Ivan'kova EM (1999) J Macromol Sci Phys B 38:859

68. Mott PH, Argon AS, Suter U (1993) Philosophical Maganzin A 67:931

69. Lemstra P, Myasnikova L (eds) (2010) Reactor powder morphology. Nova Science, Hauppauge

70. Bartczak Z, Beris PFM, Wasilewski K, Galeski A, Lemstra PJ (2011) J. Appl. Polymer Science (in press)

71. Myasnikova L (2002) 6th annual UNESCO/IUPAC conference: 14-17 April, 2003, Mpumalanga, South Africa (see also Journal of Macromolecular Science, Part B 41, 939)

72. Pruitt L (2003) Adv Polymer Sci 162:63

73. Ballauff M (1993) Materials science and technology. In: Kahrn RW, Haasen P, Kramer EJ (eds) Structure and properties of polymers, vol 12. Verlag Chemie, Weinheim, p 213

74. Wegner G (1977) Pure Appl Chem 49:443

75. Galiotis C, Read RT, Yeung PHJ, Young RJ, Calmers IF, Bloor D (1984) J Polymer Sci Polymer Physics Edition 22:1589

76. Kausch HH, Legras R (eds) (1993) Advanced thermoplastic composites, characterization and processing. Hanser, Munich

77. Balta-Calleja FJ (1993) Structure in polymers with special properties. In: Zachmann HG (ed) Adv in Polymer Sci. Springer, Berlin, p 108

78. Batzer H, Lohse F, Schmid R (1973) Angew Makromol Chemie 29:349 
79. Pascault J-P, Sautereau H, Verdu J, Williams RJJ (2002) Thermosetting polymers. Marcel Dekker, New York

80. Paul DR, Bucknall CB (eds) (1999) Polymer blends, formulation and performance. Wiley, New York

81. Zweifel H (1998) Stabilization of polymeric materials. Springer, Berlin

82. Verdu J (1984) Vieillissement des plastiques. AFNOR Technique, Paris

83. Struik LCE (1978) Physical aging of amorphous polymers and other materials. Elsevier, Amsterdam

84. Struik LCE (1997) Polymer 38:4053

85. Jannink G, Saint-James D (1968) J Chem Phys 49:486

86. Kirste RG, Kruse WA, Ibel K (1975) Polymer 16:120

87. Higgins J, Allen G, Brier PN (1972) Polymer 13:157

88. Fischer EW, Dettenmaier M (1978) J Non-Cryst Solids $31: 181$

89. Sadler DM, Keller A (1976) Polymer 17:37

90. Higgins JS, Benoit HC (1997) Polymers and neutron scattering. Clarendon, Oxford

91. Stein RS, Han CC (1985) Physics Today 38(1):74

92. Ernst R (2010) Autobiography. Nobel Media AB, London

93. Spiess HW (2002) In: Grant DM, Harris RK (eds) Encyclopedia of nuclear magnetic resonance, vol 9. Wiley, New York

94. Balta Calleja FJ, Fakirov S (2000) Microhardness of polymers. Cambridge Univ Press, Cambridge

95. Flores A, Ania F, Balta-Calleja FJ (2009) J Polymer 50:729

96. Kausch HH, Zachmann HG (eds) (1985) Characterization of polymers in the solid state, vol I/II. Adv in Polymer Sci. Springer, Berlin, p 66/67

97. Löfgren B, Kokko E, Seppälä J (2004) Long-term properties of polyolefins. In: Albertsson AC (ed) Adv in Polymer Sci, 169. Springer, Berlin, $\mathrm{p} 1$

98. Wu S (1990) Polym Eng \& Science 30:753

99. Plummer CJG, Kausch HH, Tézé L, Halary JL, Monnerie L (1996) Polymer 37:4299

100. Kausch HH (ed) (1983) Crazing in polymers I. Adv in Polymer Sci, pp 52/53

101. Michler GH (1992) Kunststoff-Mikromechanik. Hanser, München, 88

102. Narisawa I, Yee AF (1993) Materials science and technology. In: Kahrn RW, Haasen P, Kramer EJ (eds) Structure and properties of polymers, vol 12. Verlag Chemie, Weinheim, p 699

103. Wright DC (1996) Environmental stress cracking of plastics. RAPRA Technology, Shawbury

104. Plummer CG (1997) Current Trends in Polymer Sci 2:125

105. Kausch HH (ed) (1990) Crazing in polymers II. Adv in Polymer Sci, pp 91/92

106. Kramer EJ, Green P, Palmstrom C (1984) Polymer 25:473

107. Creton C, Kramer EJ, Brown HR, Hui C-Y (2002) Adv Polymer Sci $156: 53$

108. Plummer CJG (2004) Long-term properties of polyolefins. In: Albertsson AC (ed) Adv in Polymer Sci 169. Springer, Berlin, p 75

109. Pawlak A, Galeski A (2005) Macromolecules 38:9688

110. Brown N, Lu X, Huang Y-L, Quian R (1991) Makromol Chem Macromol Symp 41:55

111. Halary JL, Lauprêtre F, Monnerie L (2008) Mécanique des matériaux polymères. Belin, Paris, p 169, will be published in English: Polymer materials: macroscopic properties and molecular interpretations, 2011, Wiley, Hoboken

112. Kausch HH (ed) (2005) Intrinsic molecular mobility and toughness of polymers, Vol. I and II. Adv In Polymer Sci, pp $187+188$

113. Kremer K, Binder K (1988) Computer Physics Reports 7:259

114. Hutnik M, Argon AS, Suter U (1991) Macromolecules 24:5970
115. Herzberg R, Manson JA (1980) Fatigue of engineering plastics. Academic, New York

116. Suresh S (1991) Fatigue of materials. Cambridge Univ Press, Cambridge

117. Sauer JA, Chen CC (1983) Crazing in polymers I. In: Kausch HH (ed) Adv in Polymer Sci. Springer, Berlin, p 52/ 53

118. Pruitt L, Bull C, Suresh S (1993) In: Bailon JP (ed) Fatigue '93, 3, 1349

119. Takemori MT (1990) Crazing in polymers II. In: Kausch HH (ed) Adv in Polymer Sci. Springer, Berlin, p 91/92, 263, 169

120. Altstädt V (2005) Intrinsic molecular mobility and toughness of polymers, vol II. In: Kausch HH (ed) Adv in Polymer Sci. Springer, Berlin, p 188, 105

121. Baird DG (1999) Korea-Australia Rheology Journal 11:305

122. Meissner J, Hostettler J (1994) Rheol Acta 33:1

123. Janeschitz-Kriegl H (2010) Crystallization modalities in polymer melt processing. Springer, Vienna

124. Nguyen TQ, Kausch HH (eds) (1999) Flexible polymer chain dynamics in elongational flow. Springer, Berlin

125. Béguelin P, Kausch HH (1995) In: Williams JG, Pavan A (eds) Impact and dynamic fracture of polymers and composites. Mechanical Engineering, London

126. Takahashi K, Yee AF (eds) (1992) Impact fracture of polymers: materials science and testing techniques. Kyushu University Press, Kyushu

127. Jones RAL, Richards RW (1999) Polymers at surfaces and interfaces. Cambridge Univ Press, Cambridge

128. Tirrell M, Parsonage E (1993) Materials science and technology. In: Kahrn RW, Haasen P, Kramer EJ (eds) Structure and properties of polymers, vol 12. Verlag Chemie, Weinheim, p 653

129. Rittigstein P, Priestley RD, Broadbelt LJ, Torkelson JM (2007) Nat Mater 6:278

130. Bernal Lara TE, Ranade A, Hiltner A, Baer E (2005) In: Michler GH, Balta-Calleja FJ (eds) Mechanical properties of polymers based on nanostructure and morphology. Taylor \& Francis, Boca Raton, p 629

131. Michler GH, Balta-Calleja FJ (eds) (2005) Mechanical properties of polymers based on nanostructure and morphology. Taylor \& Francis, Boca Raton

132. Ruckdäschel H, Gutmann P, Altstädt V, Schmalz H, Müller AHE (2010) Adv Polymer Sci 227:199

133. Daniel M (2010) Multi-scale dynamics of structured polymer materials, International Workshop, Paris, Dec 6-7

134. Sue HJ (1992) J Materials Science 27:3098

135. Fredrickson GH (2011) Vision for a sustainable chemical enterprise. Quadrant Award Event, Zurich

136. Fetters LJ, Thomas EL (1993) Materials science and technology. In: Kahn RW, Haasen P, Kramer EJ (eds) Structure and properties of polymers, vol 12. Verlag Chemie, Weinheim, $\mathrm{p} 1$

137. Hotta A, Cochran E, Ruokolainen J, Khanna V, Fredrickson GH, Kramer EJ, Shin Y-W, Shimizu F, Cherian AE, Hustad PD, Rose JM, Coates GW (2006) PNAS 103:5327, originally published online Oct 10, 2006

138. Arriola D, Carnahan EM, Hustad PD, Kuhlman RL, Wenzel TT (2006) Science 312:714-719

139. Holden G, Milkovitch R (1963) Belg. Patent 627652 to Shell Int. Res. Maatschappeij (cited after [1])

140. Kawai H, Hashimoto T (1979) Contemporary Topics in Polymer Science 3:245

141. Tsarkova L, Agur Sevink GJ, Krausch G (2010) Complex macromolecular systems. Adv Polymer Sci 227:33

142. Klapper M, Nenov S, Haschick R, Muller K, Müllen K (2008) Accounts of Chemical Research 41:1190 
143. Meier MARD, Webster C (eds) (2010) Polymer libraries. Adv in Polymer Sci, pp 225

144. Balazs AC, Emrick T, Russell TP (2006) Science 314:1107

145. Müller AHE, Schmidt H-W (eds) (2010) Complex macromolecular systems I/II. Adv Polymer Sci, pp 227/228

146. Mülhaupt R (2010) Macromol Chem Phys 211:121

147. Pruitt LA, Chakravartula A (2011) Mechanics of biomaterials: fundamentals of implant design. Cambridge University Press, Cambridge
148. Kane S, Ashby PD, Pruitt LA (2010) J Materials Science: Materials in Medicine Research 21:1037

149. Andruzzi L, Senaratne W, Hexemer A, Sheets ED, Ilic B, Kramer EJ, Baird B, Ober CK (2005) Langmuir 21:2495

150. Lavanant L, Pullin B, Hubbell JA, Klok H-A (2010) Macromol Biosci 10:101

151. Klok H-A (2009) Macromolecules 42:7990

152. Alcock B, Cabrera NO (2011) Composites Part A. Applied Science and Manufacturing 37:716 